\title{
Aspectos anatomopatológicos da leptospirose em cães: 53 casos $(1965-2011)^{1}$
}

\author{
Camila Tochetto 2 , Mariana M. Flores ${ }^{2}$, Glaucia D. Kommers ${ }^{3}$, Claudio S.L. Barros ${ }^{3}$ \\ e Rafael A. Fighera ${ }^{3^{*}}$
}

\begin{abstract}
Tochetto C., Flores M.M., Kommers G.D., Barros C.S.L. \& Fighera R.A. 2012. [Pathological aspects of leptospirosis in dogs: 53 cases (1965-2011).] Aspectos anatomopatológicos da leptospirose em cães: 53 casos (1965-2011). Pesquisa Veterinária Brasileira 32(5)430-443. Departamento de Patologia, Universidade Federal de Santa Maria, Av. Roraima 1000, Santa Maria, RS 97105-900, Brazil. E-mail: anemiaveterinaria@yahoo.com.br

The pathological aspects of canine leptospirosis were studied in 53 dogs with a conclusive diagnosis of the disease, as confirmed by immunohistochemistry on renal tissue. Main necropsy lesions included icterus (79.2\%) and hemorrhage (75.5\%), mainly in the lungs (56.6\%). Gross hepatic (56.6\%) and renal (50.9\%) changes were frequently found and were characterized mainly by discoloration (respectively $30.2 \%$ and $32.1 \%$ ), accentuation of hepatic lobular pattern (26.4\%) and white streaks in the cut surface of kidneys $(22.6 \%)$. Extrarenal lesions secondary to uremia occurred in half of the cases $(50.9 \%)$. Enlarged livers $(11.3 \%)$, and kidneys (9.4\%), and rough renal capsular surfaces $(3.8 \%)$ were less common findings. In the histopathology of the kidneys $(n=53)$, the encountered lesions $(98.1 \%)$ were almost exclusively acute or subacute $(96.2 \%)$ and were characterized by varying degrees of tubular nephrosis $(86.8 \%)$ and non-suppurative interstitial nephritis $(60.4 \%)$, with evident degenerative-inflammatory dissociation. In the histopathology of the liver $(\mathrm{n}=42)$, the encountered lesions $(97.6 \%)$ consisted mainly of hepatocellular dissociation (78.6\%), intracanalicular cholestasis (33.3\%) and hepatocellular necrosis (31\%). Reactive lesions, such as Kupffer cell hypertrophy, sinusoidal leucocytostasis and inflammatory mononuclear infiltrate within portal triads were observed in several cases $(42.8 \%)$. In the histopathology of the lung $(n=28)$, alveolar hemorrhage $(85.7 \%)$ and edema $(57.1 \%)$ were rather frequent lesions. Neutrophils and macrophages in the alveolar spaces (35.7\%) and neutrophils within small pulmonary vessels $(17.9 \%)$ were also frequent findings. The findings stemming from the current study should serve as an alert for Brazilian veterinary pathologists, since the pathological presentations of canine leptospirosis in this region (Central Region of the State of Rio Grande do Sul, Brazil) did not change in the last 50 years, and is still similar to that described worldwide up to the decade of 1980 's, but rather different from that currently recognized in the United States, Canada and part of West Europe. We recommend that the histopathological criteria for the diagnosis of canine leptospirosis should include the concomitant occurrence of acute or subacute tubulointerstitial nephritis, non specific reactive hepatitis and diffuse alveolar damage, including diffuse alveolar hemorrhage with capillaritis, in a dog which at necropsy had presented icterus, hemorrhage and extrarenal lesions of uremia without splenomegaly.
\end{abstract}

INDEX TERMS: Diseases of dogs, infectology, pathology, leptospirosis, Leptospira icterohemorrhagiae.

\footnotetext{
${ }^{1}$ Recebido em 30 de janeiro de 2012.

Aceito para publicação em 22 de fevereiro de 2012.

Parte da Dissertação de Mestrado do primeiro autor.

${ }^{2}$ Programa de Pós-Graduação em Medicina Veterinária, área de concentração em Patologia Veterinária, Centro de Ciências Rurais (CCR), Univer-
}

sidade Federal de Santa Maria (UFSM), Camobi, Santa Maria, RS 97105900, Brasil.

${ }^{3}$ Departamento de Patologia, Centro de Ciências da Saúde, UFSM, Av. Roraima 1000, Santa Maria, RS 97105-900. *Autor para correspondência: anemiaveterinaria@yahoo.com.br 
RESUMO.- Os aspectos anatomopatológicos da leptospirose foram estudados em 53 cães que tiveram diagnóstico definitivo confirmado por imuno-histoquímica do tecido renal. Na necropsia, as principais lesões observadas incluíram icterícia $(79,2 \%)$ e hemorragia $(75,5 \%)$, principalmente no pulmão $(56,6 \%)$. Alterações macroscópicas hepáticas $(56,6 \%)$ e renais $(50,9 \%)$ foram frequentes e caracterizavam-se principalmente por descolorações $(30,2 \%$ e $32,1 \%$ respectivamente), acentuação do padrão lobular hepático $(26,4 \%)$ e estriações brancas na superfície de corte dos rins $(22,6 \%)$. Lesões extrarrenais de uremia ocorreram na metade dos casos $(50,9 \%)$. Hepatomegalia $(11,3 \%)$, nefromegalia $(9,4 \%)$ e irregularidade da superfície capsular dos rins $(3,8 \%)$ foram menos comuns. Na histologia dos rins $(n=53)$, as lesões encontradas $(98,1 \%)$ foram quase que exclusivamente agudas ou subagudas $(96,2 \%)$ e caracterizavam-se por graus variados de nefrose tubular $(86,8 \%)$ e nefrite intersticial não supurativa $(60,4 \%)$, com evidente dissociação degenerativo-inflamatória. $\mathrm{Na}$ histologia do fígado $(n=42)$, as lesões encontradas $(97,6 \%)$ eram constituídas principalmente por dissociação dos cordões de hepatócitos (78,6\%), colestase intra-canalicular (33,3\%) e necrose hepática (31\%). Lesões reativas, como hipertrofia das células de Kupffer, leucocitostase sinusoidal e infiltrado inflamatório mononuclear nos espaços porta, foram vistas em muitos casos $(42,8 \%)$. Na histologia do pulmão $(n=28)$, hemorragia $(85,7 \%)$ e edema $(57,1 \%)$ alveolares foram muito prevalentes. Neutrófilos e macrófagos nos espaços alveolares $(35,7 \%)$ e neutrófilos no interior de pequenos vasos pulmonares $(17,9 \%)$ também foram achados frequentes. Os resultados aqui demonstrados devem servir de alerta aos patologistas veterinários brasileiros, pois a apresentação anatomopatológica da leptospirose canina em nossa região (Região Central do Rio Grande do Sul, Brasil) não se modificou nos últimos 50 anos, mantendo-se semelhante àquela descrita internacionalmente até a década de 1980, mas muito diferente do que é atualmente reconhecido para os Estados Unidos, o Canadá e parte da Europa Ocidental. Recomendamos que os critérios histopatológicos para o diagnóstico da leptospirose canina devem incluir a presença concomitante de nefrite tubulointersticial aguda ou subaguda, hepatite reativa não específica e lesão alveolar difusa, incluindo hemorragia alveolar difusa com capilarite, em um cão que durante a necropsia demonstre icterícia, hemorragias e lesões extrarrenais de uremia na ausência de esplenomegalia.

TERMOS DE INDEXAÇÃO: Doenças de cães, infectologia, patologia, leptospirose, Leptospira icterohemorrhagiae.

\section{INTRODUÇÃO}

O diagnóstico da leptospirose pode ser realizado por diferentes técnicas, mas clinicamente os métodos baseiam-se na detecção direta ou indireta do agente ou de seu material genético (Levett 2001). A detecção de anticorpos específicos pode ser realizada pelo teste de aglutinação microscópica (MAT) ou por teste imunoenzimático (ELISA), já leptospiras podem ser detectadas por cultura da urina, microscopia de campo escuro e reação em cadeia de polime- rase (PCR) (Adler \& De La Peña-Moctezuma 2010). Embora todos esses métodos possam dar uma falsa ideia de facilidade diagnóstica, é muito comum que casos suspeitos jamais sejam confirmados. Embora haja vários motivos para isso, a morte aguda dos cães infectados é a principal causa em nossa rotina, pois inviabiliza a sorologia pareada através do MAT, o método mais recomendado ("teste padrão ouro") (Faine et al. 1999) e também o mais utilizado mundialmente no diagnóstico dessa doença (Van de Maele et al. 2008). Com base nessa problemática, quase a totalidade do diagnóstico definitivo de leptospirose em nossa região (Região Central do Rio Grande do Sul) tem sido realizado, ao longo dos anos (1965-2011), de acordo com os achados anatomopatológicos. Entretanto, muitos são os problemas enfrentados pelo patologista para realização desse diagnóstico, tais limitações incluem principalmente casos em que as lesões são escassas e aqueles em que técnicas da impregnação pela prata (por exemplo, Warthin-Starry) (Adin \& Cowgill 2000) têm resultados duvidosos. A consequência disso pode ser contemplada na forma de resultados falso-positivos e falso-negativos e principalmente na arbitrariedade em firmar o diagnóstico definitivo à necropsia.

Embora leptospirose seja reconhecidamente uma das doenças infecciosas mais frequentemente descritas em cães e sua alta prevalência na Região Central do RS a coloque como a quarta doença infecciosa mais letal para essa espécie (Fighera et al. 2008), não existem critérios morfológicos para a realização do diagnóstico definitivo com base apenas na necropsia, o que têm colocado essa doença como um desafio ao patologista. Assim, o objetivo principal deste trabalho é estabelecer critérios anatomopatológicos para o diagnóstico da leptospirose, a fim de minimizar os problemas relacionados a essa doença na rotina do diagnóstico em patologia.

\section{MATERIAL E MÉTODOS}

Os casos incluídos neste trabalho ocorreram entre 1965 e 2011, no Município de Santa Maria, localizado na Mesorregião do Centro Ocidental Rio-Grandense, popularmente conhecida como Região Central do RS. Foram considerados apenas casos espontâneos e fatais da doença $(n=53)$.

0 método de inclusão dos casos no estudo seguiu a seguinte sistemática: 1) foram resgatados do arquivo do Laboratório de Patologia Veterinária da Universidade Federal de Santa Maria (LPV-UFSM) todos os casos diagnosticados como leptospirose no referido período, independentemente dos critérios utilizados no diagnóstico por cada patologista $(n=135) ; 2)$ foram reavaliados histologicamente todos os casos em que os blocos de parafina foram encontrados ( $n=112)$; 3) foram selecionados apenas os casos em que haviam lesões reconhecidas na literatura como associadas à leptospirose ( $\mathrm{n}=103)$; 4) desses casos, apenas aqueles em que havia blocos de parafina de tecido renal foram incluídos $(n=81)$; 5) foi realizada imuno-histoquímica ${ }^{4}$ para confirmação do diagnóstico definitivo apenas nos casos em que o tecido renal foi considerado viável em quantidade e qualidade $(n=79)$; 6) os casos positivos foram identificados e correspondem aos resultados aqui demonstrados $(n=53)$.

\footnotetext{
${ }^{4}$ Serotec $5633-4956^{\circledR}$, AbD Serotec, Business Park, Langford Lane, Kidlington, OX5 1GE, Oxford, Oxfordshire, UK.
} 


\section{RESULTADOS}

\section{Achados de necropsia}

Na necropsia $(n=53)$, a maior parte dos cães $(42 / 53$ $[79,2 \%])$ apresentava icterícia, que se caracterizava por graus variáveis de amarelamento das mucosas externamente visíveis (oral [Fig.1], conjuntival e genital), do tecido subcutâneo, das serosas, da íntima de grandes artérias e, nos casos mais graves, da pele, do periósteo, da cápsula articular, da esclera e das meninges. Algum grau de hemorragia foi observado em boa parte dos cães (40/53 [75,5\%]). Essas hemorragias ocorriam na forma de petéquias e sufusões (incluindo víbices) e afetavam vários órgãos, de forma isolada ou multicêntrica, mas principalmente o pulmão (30/53 [56,6\%]). Hemorragias cavitárias, na forma de hemotórax (3/53 [5,7\%]), hemoperitônio $(1 / 53$ [1,9\%]) e hemopericárdio $(1 / 53[1,9 \%])$, também foram ocasionalmente observadas. Muitos dos cães (36/53 [67,9\%]) apresentavam, concomitantemente, icterícia e hemorragia.

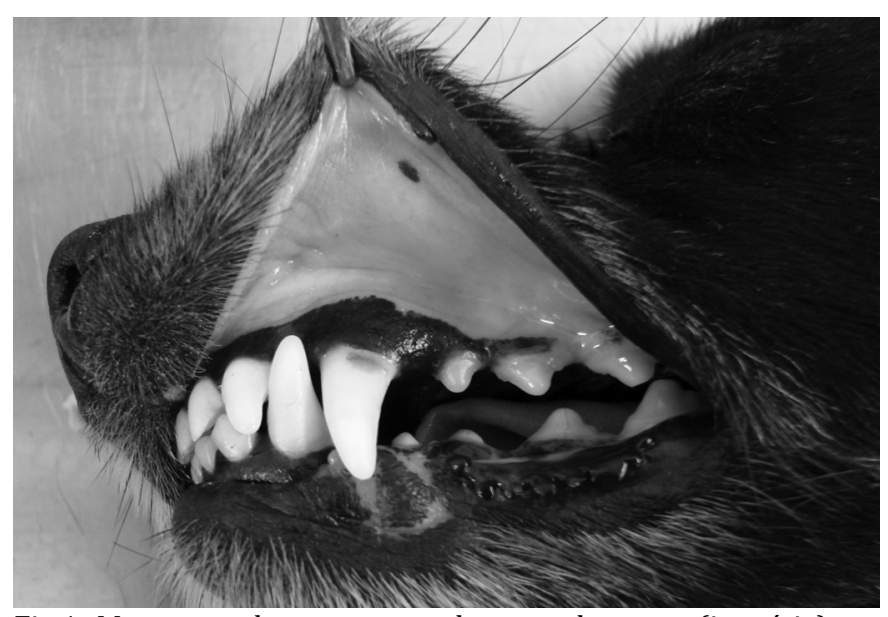

Fig.1. Mucosa oral com acentuado amarelamento (icterícia), na leptospirose canina.

O fígado apresentava alterações macroscópicas em vários cães (30/53 [56,6\%]). Essas alterações incluíam, em ordem decrescente de frequência: mudança na cor do órgão (fígados descritos como pálido, amarelo, amarelado, vermelho-tijolo, vermelho-alaranjado, marrom-alaranjado e esverdeado) (16/53 [30,2\%]) (Fig.2), acentuação do padrão lobular (14/53 [26,4\%]) (Fig.3) e aumento difuso de volume (hepatomegalia) $(6 / 53$ [11,3\%]). Hemorragias na vesícula biliar, incluindo a presença de bile com sangue (Fig.4), foram observadas em poucos casos (3/53 [5,7\%]).

Alterações renais macroscópicas foram vistas em cerca de metade dos cães $(27 / 53[50,9 \%])$. Descolorações (rins descritos como amarelos, amarelados, pálidos, esverdeados ou verdes) foram os achados mais frequentes $(17 / 53$ [32,1\%]) (Fig.5), seguidas de estriações brancas na superfície de corte $(12 / 53$ [22,6\%]), aumento difuso de volume (nefromegalia) (5/53 [9,4\%]) e discreta irregularidade da superfície capsular (2/53 [3,8\%]). Hemorragias na superfície capsular (Fig.6) foram observadas em poucos casos (3/53 [5,7\%]).

Lesões extrarrenais de uremia foram observadas em aproximadamente a metade dos cães $(27 / 53$ [50,9\%]) e incluíam: gastropatia urêmica $(22 / 53$ [41,5\%]), enteropa- tia urêmica $(14 / 53[26,4 \%])$, pneumopatia urêmica $(4 / 53$ $[7,5 \%])$, mineralização da pleura parietal $(3 / 53[5,7 \%])$, glossite ulcerativa $(2 / 53$ [3,8\%]), endocardite mural ulcerativa $(2 / 53[3,8 \%])$, mineralização da íntima da artéria aorta e hiperplasia difusa das glândulas paratireoides (1/53 [1,9\%]).

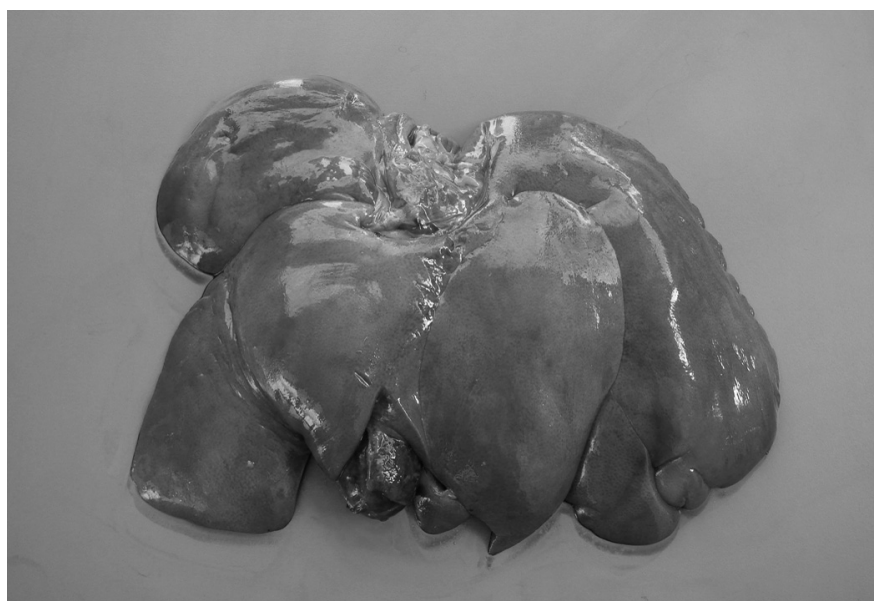

Fig.2. Fígado vermelho-alaranjado, uma forma de descoloração difusa frequentemente denominada pela coloquial expressão "fígado cor de tijolo", na leptospirose canina.

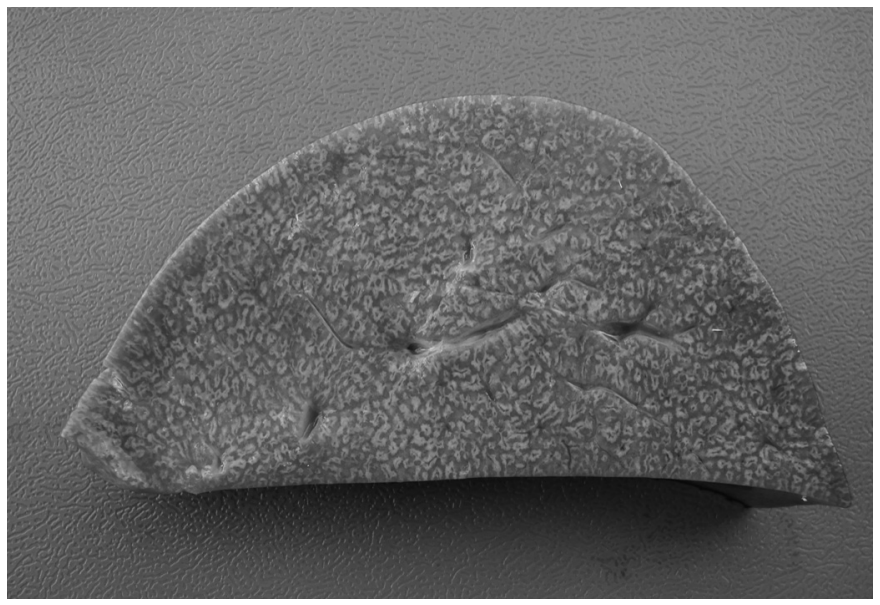

Fig.3. Marcada acentuação do padrão lobular do fígado, na leptospirose canina.

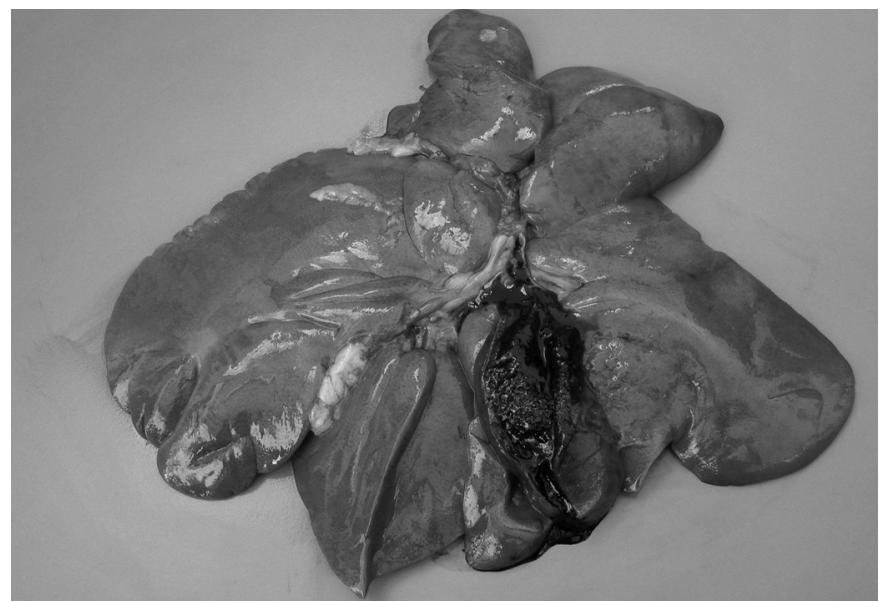

Fig.4. A vesícula biliar está aberta deixando fluir bile com sangue e o fígado demonstra a mesma descoloração vista na Figura 2, na leptospirose canina. 
Havia edema pulmonar em aproximadamente a metade dos cães (22/53 [41,5\%]) (Fig.7) e, em pelo menos um quarto dos casos $(14 / 53[26,4 \%])$, edema e hemorragia ocorreram simultaneamente no pulmão (Fig.8). Nesses casos, os pulmões não colapsaram quando a cavidade torácica foi aberta; eram pesados, úmidos, brilhantes, difusamente vermelho-escuros, deixavam fluir muito líquido quando cortados e apresentavam variável quantidade de espuma amarela, rósea ou vermelha no interior da traqueia e dos grandes brônquios. Hidrotórax, hidropericárdio e ascite foram observados apenas ocasionalmente $(5 / 53$ [9,4\%], $4 / 53$ [7,5\%] e $2 / 53$ [3,8\%], respectivamente).

Achados de necropsia menos prevalentes incluíram: caquexia (6/53 [11,3\%]), linfadenomegalia generalizada (5/53 $[9,4 \%])$, necrose da gordura abdominal $(4 / 53$ [7,5\%]), palidez das mucosas e sangue aquoso $(2 / 53[3,8 \%])$, tonsilomegalia $(1 / 53$ [1,9\%]) e intussuscepção $(1 / 53$ [1,9\%]).

\section{Achados histopatológicos}

Nos rins ( $n=53)$, as lesões encontradas (52/53 [98,1\%]) foram quase que exclusivamente agudas ou subagudas $(51 / 53[96,2 \%])$ e caracterizavam-se por graus variados de degeneração e necrose do epitélio tubular (nefrose tubular) (46/53 [86,8\%]) (Fig.9). Nos casos graves (15/53 [28,3\%]) havia grande quantidade de debris celulares e cilindros (hialinos e/ou granulares) obstruindo parcial ou totalmente a luz dos túbulos (obstrução tubular), já nos casos leves $(14 / 53$ [26,4\%]) a moderados $(17 / 53$ [32,1\%]) havia apenas proteinose tubular, pequena quantidade de células necróticas na luz dos túbulos e/ou cilindros esparsos. Em muitos casos (32/53 [60,4\%]) havia variável grau de inflamação intersticial constituída predominantemente por linfócitos e plasmócitos, mas também por macrófagos e raros neutrófilos (Fig.10). A nefrite intersticial foi dividida de acordo com a intensidade do infiltrado da seguinte maneira: leve $(14 / 53$ [26,4\%]), moderada $(11 / 53$ [20,8\%]) e acentuada (7/53 $[13,2 \%])$. Quase sempre a nefrite intersticial foi acompanhada de algum grau de nefrose tubular $(27 / 32$ [84,4\%]), caracterizando nefrite tubulointersticial, mas muitos casos de nefrose tubular ocorreram isoladamente (19/46 [41,3\%]).

Lesões renais menos frequentemente observadas incluíram: mineralização $(7 / 53$ [13,2\%]), ectasia tubular, aglomerados de neutrófilos intratubulares, cristais intratubulares, pigmento biliar no interior dos túbulos e regeneração

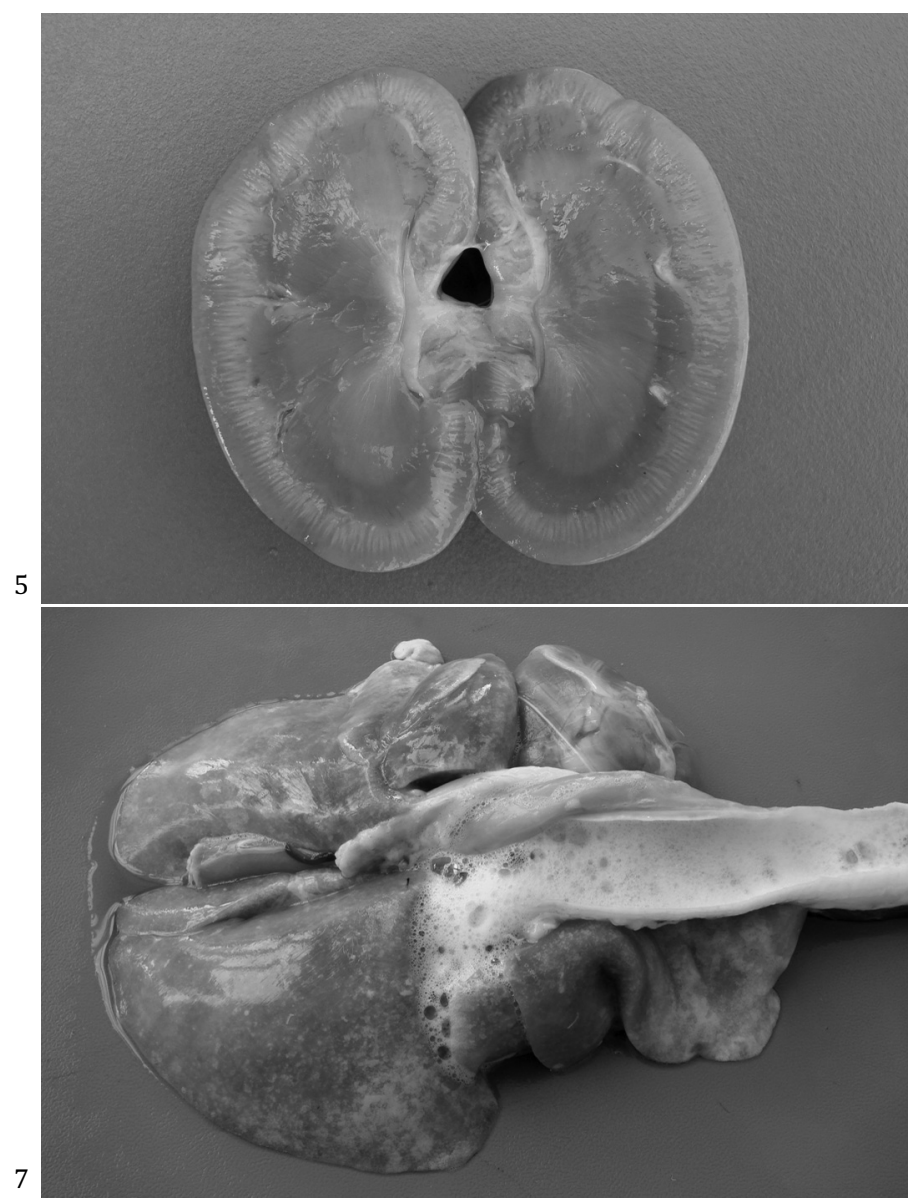

Fig.5. Intenso amarelamento cortical e medular do rim, na leptospirose canina.

Fig.7. No pulmão, a ausência em colapsar associada ao aspecto úmido e brilhante é típica dessa forma de apresentação, comumente denominada pela coloquial expressão "pulmão armado"; na traqueia há acentuada quantidade de espuma branca (edema pulmonar). Caso de leptospirose canina.

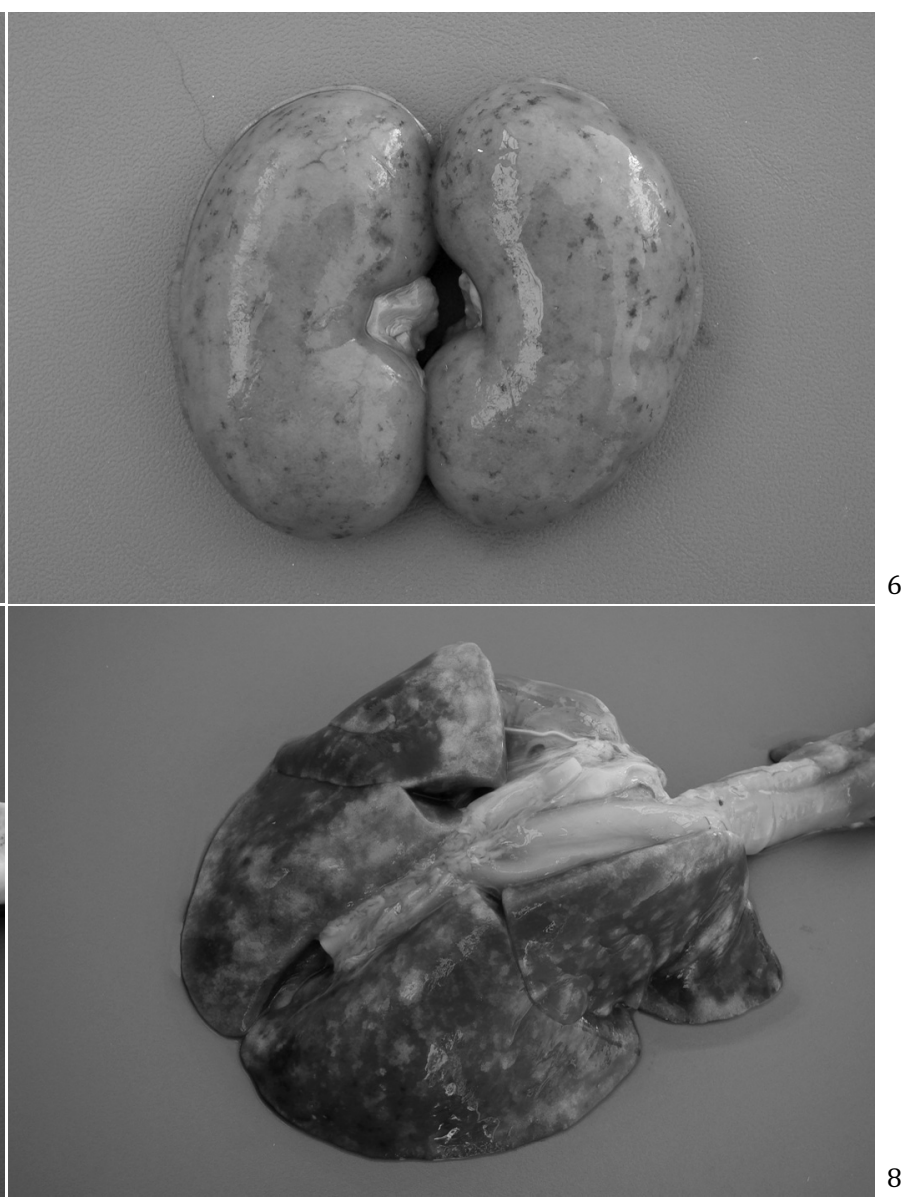

Fig.6. Hemorragias multifocais em um rim amarelo-pálido, na leptospirose canina.

Fig.8. Clássica hemorragia pulmonar, uma lesão muito comum e que no passado foi descrita como "hemorragia em asa de borboleta", em uma alusão à simetria vista nas asas desse inseto. 


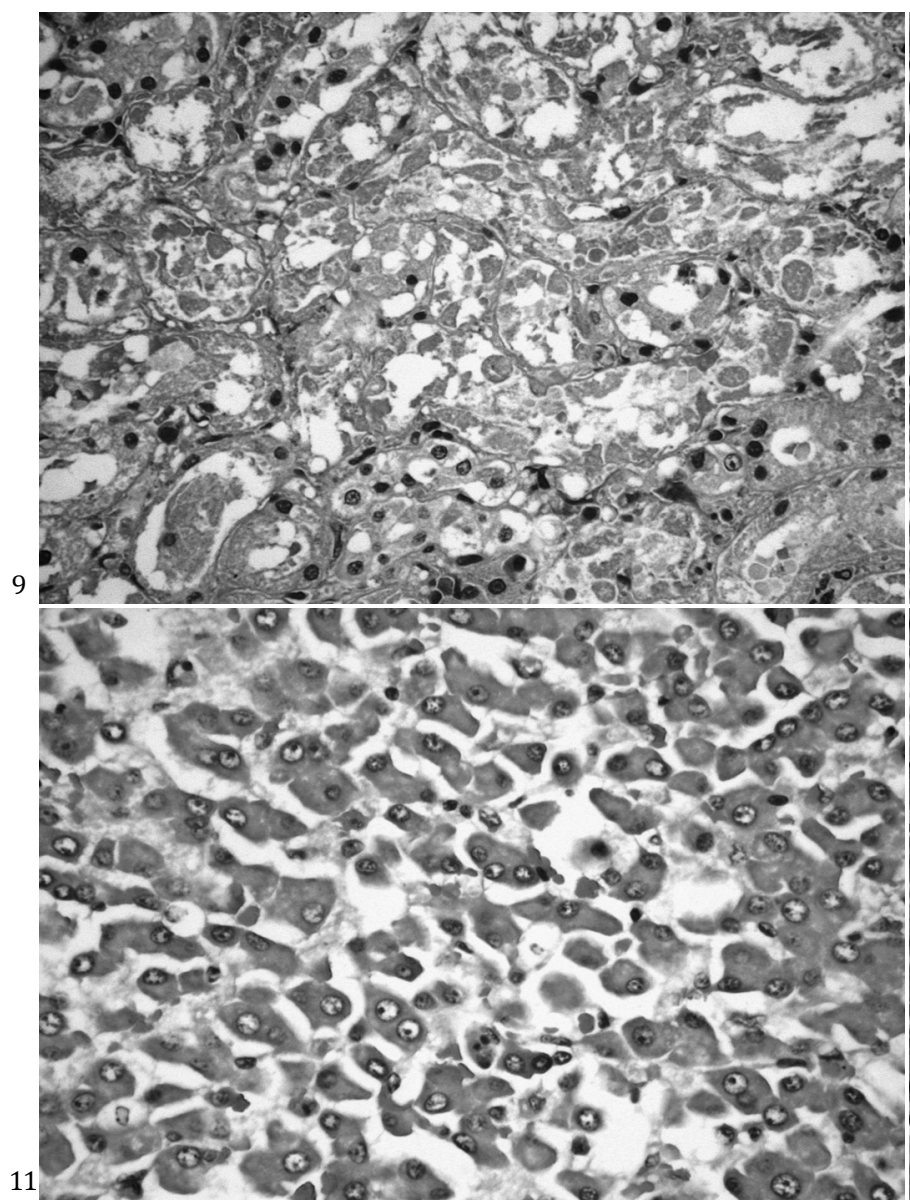

Fig.9. Acentuada degeneração e necrose das células epiteliais tubulares no rim, na leptospirose canina. HE, obj.20x.

Fig.11. Acentuada dissociação dos cordões de hepatócitos em um fígado com número aumentado de hepatócitos binucleados, na leptospirose canina. HE, obj.20x.

tubular (4/53 [7,5\%]). A mineralização foi observada nos túbulos contornados na camada cortical $(6 / 53$ [11,3\%]), na média das arteríolas $(2 / 53[3,8 \%])$ e/ou nos túbulos coletores da camada medular $(1 / 53[1,9 \%])$. Glomerulonefrite membranoproliferativa $(2 / 53[3,8 \%])$, fibrose intersticial com atrofia tubular, necrose fibrinoide de arteríolas e nefrite embólica foram observadas apenas ocasionalmente $(1 / 53$ [1,9\%]). Apenas um cão (1/53 [1,9\%]) não apresentou lesão renal.

No fígado $(n=42)$, as lesões encontradas $(41 / 42$ [97,6\%]) eram constituídas principalmente por dissociação dos cordões de hepatócitos (33/42 [78,6\%]) (Fig.11) e acúmulo de pigmento biliar (14/42 [33,3\%]), basicamente no interior dos canalículos (Fig.12). Necrose hepática pôde ser vista em vários casos (13/42 [31\%]) e foi subdividida em: necrose hepatocelular individual (8/42 [19\%]) (Fig.13), necrose hepatocelular aleatória $(4 / 42[9,5 \%])$ e necrose hepatocelular zonal (padrão centrolobular) $(3 / 42[7,1 \%])$. Em alguns casos $(11 / 42[26,2 \%])$, havia hipertrofia das células de Kupffer; em pelo menos cinco fígados $(11,9 \%)$ essa lesão estava associada à eritrofagocitose (Fig.14). Adicio-

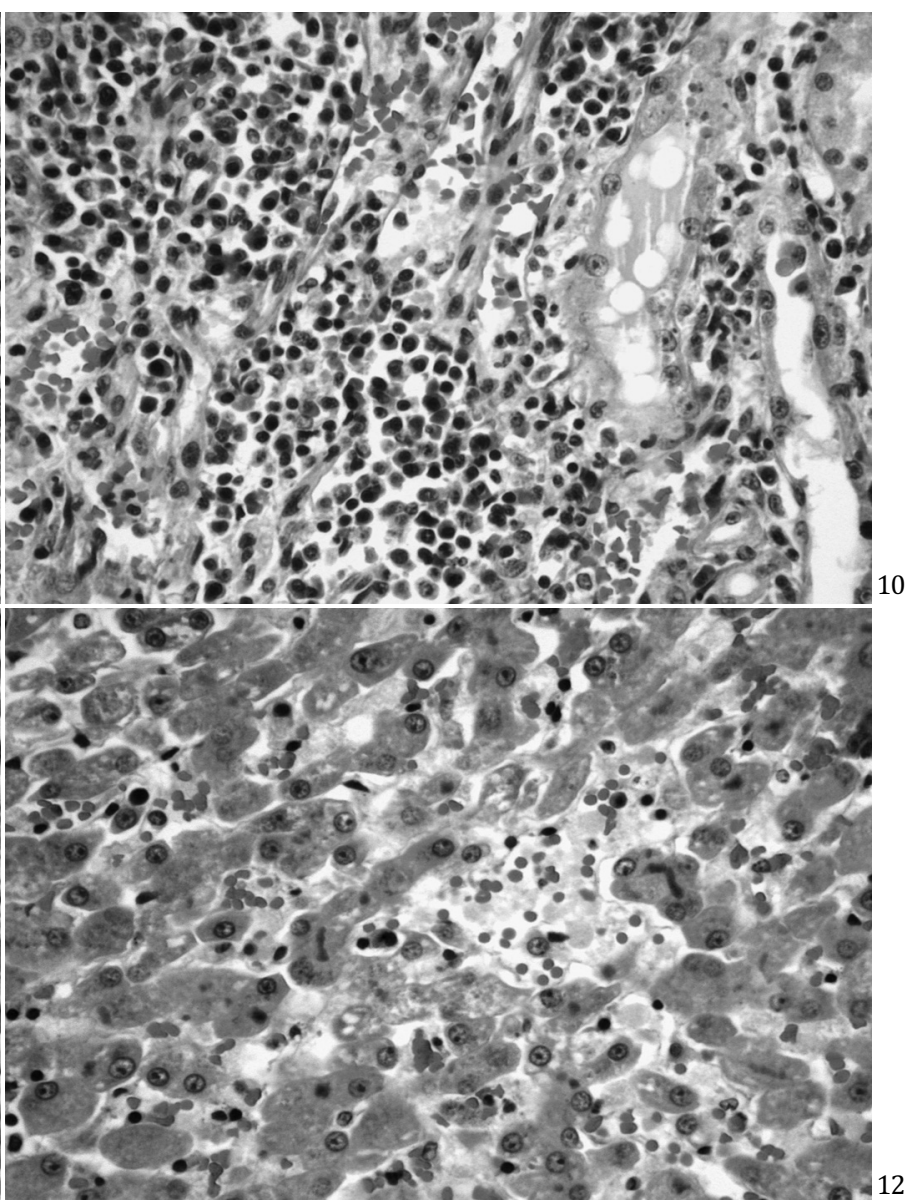

Fig.10. Infiltrado inflamatório mononuclear, predominantemente plasmocítico, no interstício renal, na leptospirose canina. HE, obj.20x.

Fig.12. Pigmento biliar no interior dos canalículos e no citoplasma de hepatócitos; em algumas áreas pode ser notado acúmulo de bilirrubina na forma de estruturas que vagamente lembram microtrombos ("trombos de bile"). Caso de leptospirose canina. HE, obj.20x.

nalmente, foi observada degeneração vacuolar de hepatócitos $(9 / 42[21,4 \%])$, neutrófilos no interior dos sinusoides (leucocitostase sinusoidal) (7/42 [16,7\%]) (Fig.15), infiltrado inflamatório mononuclear nos espaços porta $(3 / 42$ $[7,1 \%])$, aumento do número de hepatócitos binucleados $(2 / 42[4,8 \%])$ e em mitose $(2 / 42[4,8 \%])$ e infiltrado inflamatório mononuclear na forma de agregados aleatórios no parênquima (pseudogranuloma de células de Kupffer) $(2 / 42[4,8 \%])$. Apenas um cão $(1 / 42$ [2,4\%]) não apresentou lesão hepática.

No pulmão $(n=28)$, hemorragia $(24 / 28[85,7 \%])$ e edema (16/28 [57,1\%]) alveolares foram as lesões histológicos mais prevalentes. À semelhança dos achados macroscópicos, observamos que pelo menos a metade dos cães $(14 / 28$ [50\%]) demonstravam, simultaneamente, edema pulmonar e hemorragia. Dos casos em que havia edema pulmonar, dois padrões histológicos distintos puderam ser identificados. No mais comum deles $(12 / 28$ [42,9\%]), havia variável quantidade de material granular e fracamente eosinofílico (filamentos de fibrina) (Fig.16) ou de lamelas concêntricas e fortemente eosinofílicas (coágulos de fibrina) (Fig.17) que 
obliteravam a luz alveolar (fase exsudativa da lesão alveolar difusa) e hemorragia alveolar moderada a acentuada (Fig.18). Em quase todos esses casos havia neutrófilos e macrófagos nos espaços alveolares $(10 / 28$ [35,7\%]) e em alguns deles (5/28 [17,9\%]) havia agregados de neutrófilos no interior de microvasos pulmonares de paredes variavelmente hialinizadas (capilarite) (Fig.19). Em poucos casos $(2 / 28[7,1 \%])$ havia hiperplasia de pneumócitos tipo II e formação de membranas hialinas. No padrão pulmonar menos comum (4/28 [14,3]), havia edema associado à marcada mineralização dos septos alveolares. Nessa apresentação, neutrófilos e pequena quantidade de fibrina podiam ser evidenciados apenas ao redor dos septos alveolares mineralizados (pneumopatia urêmica). Com base na ausência de hemossiderina em todos os pulmões afetados pela hemorragia, as lesões pulmonares foram consideradas agudas.

\section{Achados imuno-histoquímicos}

$\mathrm{Na}$ imuno-histoquímica, dos 79 rins testados, 53 $(67,1 \%)$ foram positivos. Quanto à intensidade, a maior

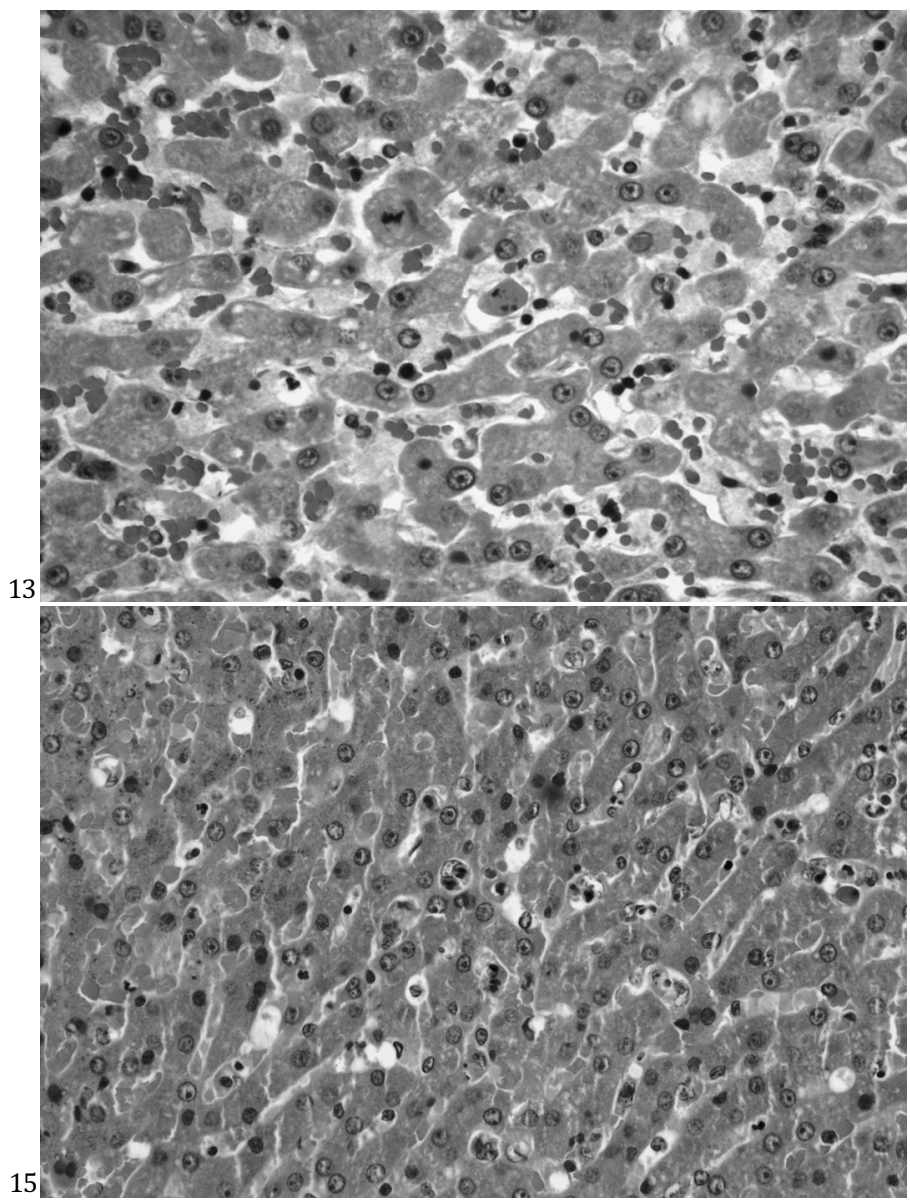

Fig.13. Necrose hepatocelular individual é evidenciada ao centro dessa figura, onde se pode observar um hepatócito com hipereosinofilia citoplasmática e fragmentação nuclear; há também colestase e mitose. Caso de leptospirose canina. HE, obj.20x.

Fig.15. Presença de grande quantidade de neutrófilos no interior dos sinusoides hepáticos; assim como a necrose individual de hepatócitos (Fig.13) e a hipertrofia de células de Kupffer (Fig.14), essa lesão é um indicativo de hepatite reativa não específica. HE, obj.20x. parte dos casos foi considerado como moderada (35/53 [66\%]). Marcação leve (16/53 [30,2\%]) e acentuada (2/53 [3,8\%]) foram menos comuns. Quanto à localização, quase a totalidade dos rins demonstrou imunomarcação intratubular (50/53 [94,3\%]). Em alguns casos ocorreu imunomarcação intraglomerular $(4 / 53$ [7,5\%]) ou intersticial $(8 / 53[15,1 \%])$. Três padrões morfológicos de imunomarcação foram observados: 1) filamentar, visualizado exclusivamente na luz tubular; 2) granular, observado tanto no citoplasma das células epiteliais tubulares e dos macrófagos quanto na luz dos túbulos, local em que a grande quantidade de grânulos frequentemente formava agregados densos e bastante evidentes (Fig.20); 3) homogêneo, caracterizado por preenchimento difuso do citoplasma dos macrófagos.

\section{DISCUSSÃO}

Os achados anatomopatológicos observados nestes 53 casos de leptospirose são semelhantes aos descritos na literatura internacional, entretanto, importantes diferenças foram observadas, novas lesões descritas e algumas reco-

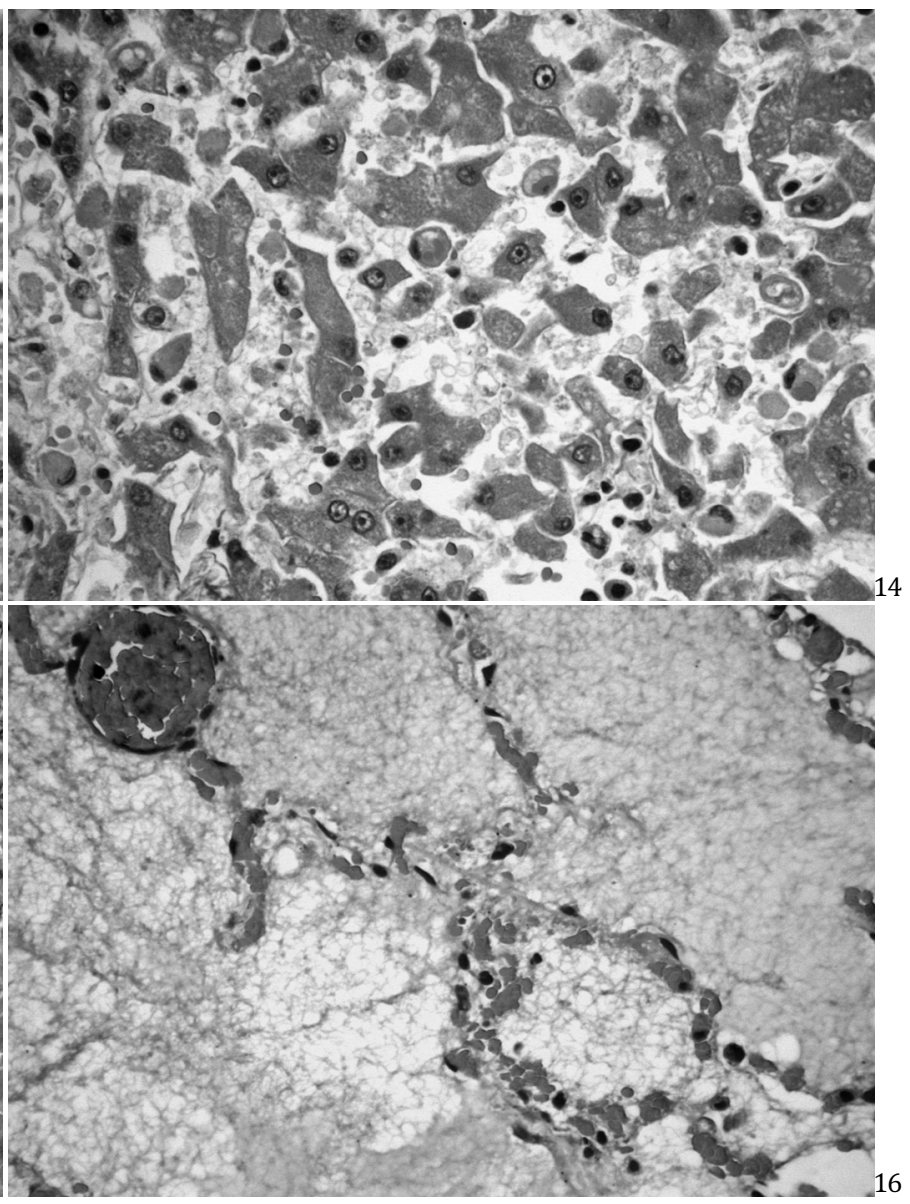

Fig.14. Fígado com hipertrofia de células de Kupffer; há eritrócitos no citoplasma de algumas dessas células (eritrofagocitose). Dissociação acentuada dos cordões de hepatócitos também é observada nessa imagem. Caso de leptospirose canina. HE, obj.20x.

Fig.16. No pulmão há material granular e fracamente eosinofílico (filamentos de fibrina) obliterando completamente os espaços alveolares. HE, obj.20x. 


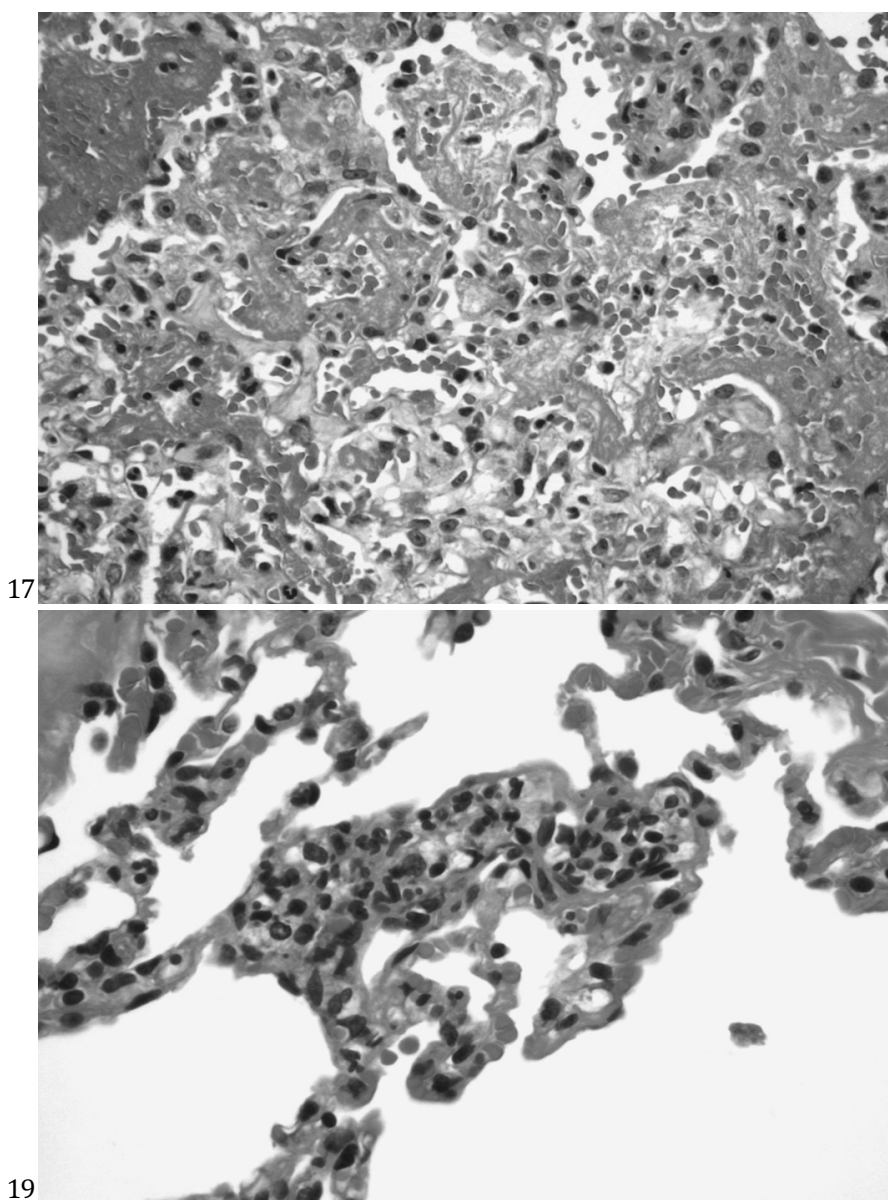

Fig.17. Pulmão com lamelas concêntricas e fortemente eosinofílicas (coágulos de fibrina) obscurecendo a arquitetura alveolar. Esse padrão, assim como o demonstrado na Figura 16, caracteriza a fase exsudativa da lesão alveolar difusa. HE, obj.20x.

Fig.19. Pulmão com presença de agregados de neutrófilos no interior de microvasos (capilarite pulmonar). HE, obj.40x.

mendações feitas a fim de melhorar o diagnóstico anatomopatológico. Tais aspectos norteiam essa discussão e são determinantes para as conclusões.

No Brasil, notoriamente, clínicos e patologistas consideram icterícia e hemorragias como lesões típicas de leptospirose, principalmente quando relacionadas à infecção com o sorovar icterohemorrhagiae. Esse conhecimento advém basicamente de livros-texto de clínica médica de pequenos animais (Hoskins 1990, Ettinger 1992, Nelson \& Couto 1992) e de patologia veterinária (Jubb \& Kennedy 1970, Niebele \& Cohrs 1970, Manninger \& Mócsy 1973, Thomson 1988) publicados até o final da década de 1980 e início da década de 1990. Tais livros, muito adotados nas escolas de veterinária do país, colocam leptospirose como uma doença que se caracteriza por icterícia, hemorragia e uremia, já que os autores dos capítulos que contemplam o tema (Jubb \& Kennedy 1970, Niebele \& Cohrs 1970, Manninger \& Mócsy 1973, Searcy 1988, Center et al. 1990, Lappin 1992, Swango et al. 1992) tratam-na como uma doença que cursa com algum grau de lesão hepática, vascular e renal, o que explica, respectivamente, tais síndromes clinicopatológicas. Entretanto, edições mais recentes de alguns

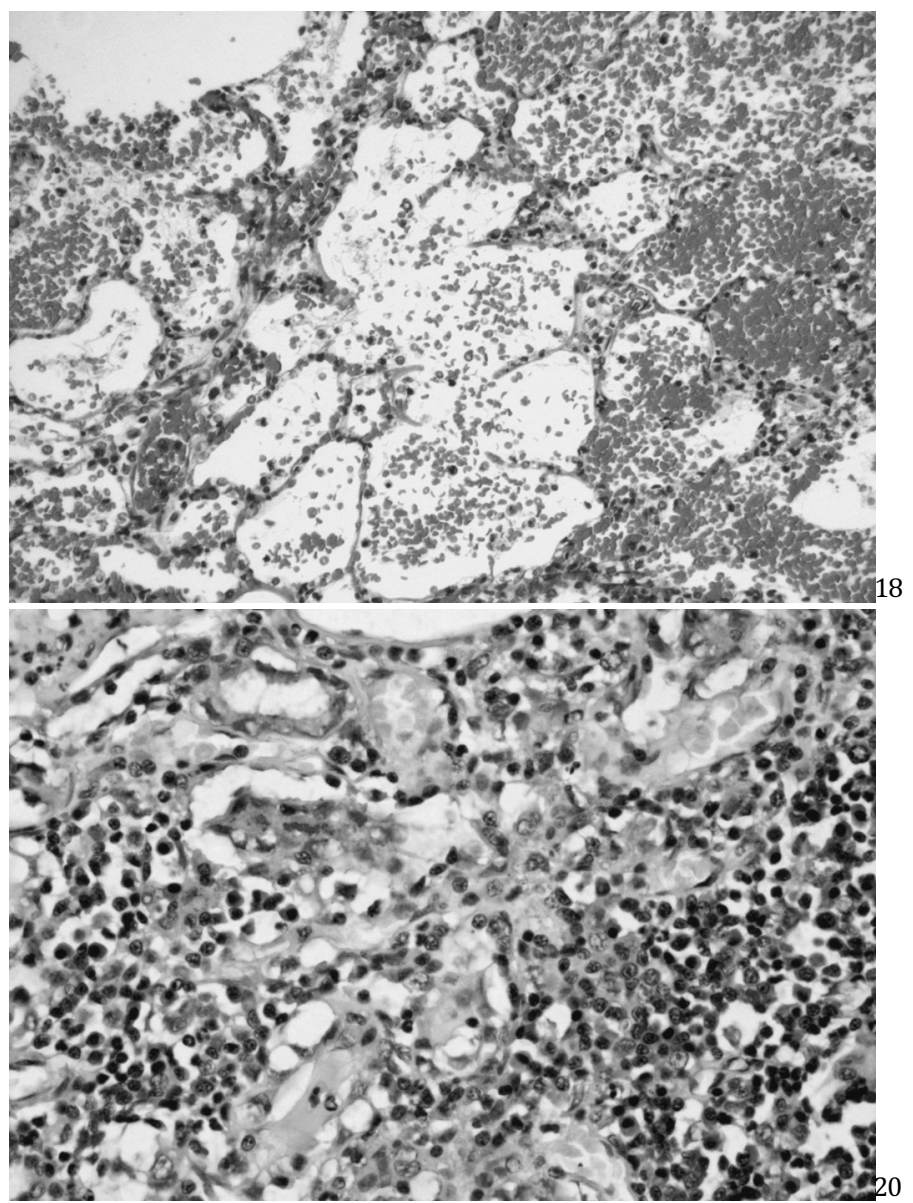

Fig.18. Pulmão com grande quantidade de eritrócitos nos espaços alveolares (hemorragia alveolar aguda). HE, obj.20x.

Fig.20. No rim, imunorreatividade é observada na forma de densos agregados vermelhos no lúmen tubular e de grânulos esparsos no citoplasma de macrófagos, na leptospirose canina. Imuno-histoquímica (método da estreptavidina-biotina-fosfatase alcalina), obj.20x.

desses mesmos livros (Ettinger \& Feldman 2004, Maxie 2007, McGavin \& Zachary 2007), assim como de outros não menos famosos (Greene et al. 2006), de meados da década de 1990 em diante, não apresentam mais leptospirose como uma doença primariamente associada à icterícia ou à hemorragia, apenas descrevem tais achados com baixa prevalência, dando ênfase principalmente à síndrome urêmica (Greene 2004, Prescott 2007, Newman et al. 2007), à semelhança do que ocorre na maior parte dos relatos de casos mais recentes (Hrinivich \& Prescott 1997, Birnbaum et al. 1998, Kalin et al. 1999, Prescott et al. 2002).

Atualmente, uma forma muito comum de conduta médica utiliza o já consagrado método conhecido como "abordagem associada ao problema", introduzido na medicina veterinária na década de 1990 (Lorenz 1996). Assim, livros que contemplam listas de diagnóstico diferencial vêm ganhando espaço cada vez maior na clínica de pequenos animais (Gough 2009). Interessantemente, da mesma forma com que vem ocorrendo com os livros-textos, nos quais eles claramente baseiam-se, listas de doenças que cursam com hemorragia ou icterícia já não mais incluem leptospirose. Essa mudança dramática na abordagem da 
mesma doença em um curto intervalo de tempo deve-se à raridade com que leptospirose decorrente de infecção pelas cepas tradicionais (icterohemorrhagiae e canicola) ocorre atualmente nos Estados Unidos e Canadá (Bunch 2004). Contrapondo isso, leptospirose é atualmente uma doença re-emergente nesses dois países (Prescott et al. 2002), porém, com sinais clínicos e achados anatomopatológicos diferentes dos que eram vistos no passado, quando leptospirose associada ao sorovar icterohemorrhagiae era enzoótica (Meyer et al. 1939, Newman 1950, Alexander et al. 1957, Braun 1961, Kravis \& Ivler 1961, Hubbert \& Shotts 1966, Thomas \& Evans 1967, Benoit 1970, Chernesky 1970, Thiermann 1980). Prova disso é que os sinais clínicos de leptospirose canina disponíveis no site do Centers for Disease Control and Prevention (CDC) nem sequer incluem icterícia e hemorragia (CDC 2012). Para muitos autores (Prescott et al. 1991, Rentko et al. 1992, Bolin 1996, Brown et al. 1996, Harkin \& Gartrell 1996, Wohl 1996, Mikaelian et al. 1997, Birnbaum et al. 1998, Warshawsky et al. 1998, Kalin et al. 1999, Prescott et al. 1999, Adin \& Cowgill 2000, Ribotta et al. 2000, Prescott et al. 2002, Ward 2002, Langston \& Heuter 2003, Stokes \& Forrester 2004, Ward et al. 2004, André-Fontaine 2006, Moore et al. 2006, Ghneim et al. 2007, Brown \& Prescott 2008, Prescott 2008, Van de Maele et al. 2008, Sykes et al. 2011), isso decorre do fato que a vacinação contra leptospirose tornou-se efetiva a ponto da doença causada pelos sorovares contemplados na maioria das vacinas (icterohemorrhagiae e canicola) estar se extinguindo, enquanto uma nova forma de apresentação clinicopatológica de leptospirose, causada por outros sorovares, principalmente grippotyphosa e pomona, surge, possivelmente pelo contato cada vez mais constante entre cães e mamíferos selvagens, principalmente racuns (Procyon lotor) e skunks (Mephitis mephitis). Nessa mesma linha de raciocínio, estudos recentes demonstram estabilização na quantidade de novos casos no Canadá entre 2002 e 2004 e decréscimo a partir desse ano, talvez pela introdução dos sorovares grippotyphosa e pomona nas vacinas desse país a partir de 2001 (Alton et al. 2009). Diferentemente, no sul do Brasil, trabalhos têm demonstrado que os sorovares $c a$ nicola e icterohemorrhagiae ainda são os mais prevalentes (Avila et al. 1998), à semelhança do que ocorre em outros países, como no México (Jimenez-Coello et al. 2008) e no Japão (Iwamoto et al. 2009).

Diversas são as doenças que como a leptospirose também cursam com icterícia ou com algum tipo de distúrbio hemorrágico em cães. Em nossa região, os principais diagnósticos diferenciais para leptospirose deverão incluir: rangeliose, babesiose, erlichiose monocitotrópica aguda e hepatite infecciosa canina (Fighera et al. 2010). Em relação à infecção por Rangelia vitalii, Babesia spp. e Ehrlichia canis existem algumas diferenças marcantes que permitem estabelecer o diagnóstico definitivo. Nessas três doenças, os achados clínicos e hematológicos associados às lesões observadas na necropsia são típicos de anemia hemolítica. Assim, apesar de macroscopicamente semelhantes, a presença de esplenomegalia deverá sempre atentar para hemólise, permitindo descartar leptospirose. A diferenciação entre essas três outras doenças deve levar em conta a presença (babesiose) ou a ausência (rangeliose e erliquiose) de nefrose hemoglobinúrica e a pesquisa dos microorganismos causadores em esfregaços sanguíneos e nas impressões de órgãos realizadas durante a necropsia (Fighera \& Graça 2011). Por fim, na histologia, essas enfermidades são completamente diferentes de leptospirose (Fighera et al. 2010). Na hepatite infecciosa canina, hemorragia é comum (Inkelmann et al. 2007), mas icterícia é observada apenas ocasionalmente, como quando os cães desenvolvem doença subaguda a crônica (Barros \& Fighera 2011). Histologicamente, a presença de corpúsculos de inclusão, vista em $100 \%$ dos casos (Inkelmann et al. 2008), facilita a diferenciação.

Na necropsia, as lesões observadas nos rins e no fígado são semelhantes àquelas classicamente descritas (Greene et al. 2006), entretanto, a literatura acerca da macroscopia da leptospirose é tão pobre que antigos capítulos de livros de medicina interna de pequenos animais (Center et al. 1990, Swango et al. 1992) trazem tanta informação quantos aqueles destinados à patologia (Cullen 2007, Newman et al. 2007, Prescott 2007, Stalker \& Hayes 2007). Estudos retrospectivos que descrevam as lesões de necropsia e suas prevalências na leptospirose canina não são encontrados na literatura disponível, o que torna impossível comparar a prevalência de nossos achados macroscópicos.

$\mathrm{Na}$ histologia, as lesões renais por nós encontradas assemelham-se às descritas por outros autores (Greene et al. 2006, Newman et al. 2007, Prescott 2007), entretanto, a literatura internacional mais recente (Sykes et al. 2011) vem dando muito mais ênfase à inflamação do que a degeneração. Nefrose tubular e nefrite intersticial foram observadas em mais de $85 \%$ e em cerca de $60 \%$ dos casos, respectivamente. 0 que chama a atenção nesses achados é o predomínio da lesão degenerativa em relação à inflamatória, pois quase todos os cães $(84,4 \%)$ com nefrite intersticial apresentavam algum grau de nefrose tubular, mas o inverso foi desproporcional, pois apenas cerca da metade dos cães $(58,7 \%)$ com lesão necrótica também tinham algum grau de inflamação. Essa dissociação degenerativo-inflamatória vai ao encontro do que almejam alguns autores ao afirmar que quanto mais aguda a lesão, maior o grau de degeneração e necrose, enquanto mais tardiamente, no estágio subagudo a crônico, predomina inflamação mononuclear (Newman et al. 2007). Com base nisso, e na macroscopia da maior parte dos rins avaliados, acreditamos que basicamente todos os casos aqui descritos têm evolução aguda ou, no máximo, subaguda. Cabe ressaltar que em apenas 3,8\% dos casos havia glomerulonefrite e que, mesmo nesses casos, havia lesão tubulointersticial associada. Isso é relevante, pois recentemente um artigo científico (Ortega-Pacheco et al. 2008) demonstrou glomerulonefrite em $94,3 \%$ dos cães submetidos à necropsia $(n=122)$, um resultado completamente diferente de tudo que se conhece acerca da patologia da leptospirose.

No fígado, dissociação dos cordões de hepatócitos e colestase intra-canalicular foram as principais lesões histológicas observadas. Para vários autores (Jones et al. 2000, Cullen 2007, Prescott 2007, Stalker \& Hayes 2007), dissociação de hepatócitos é uma alteração comum na leptospi- 
rose, mas não específica, pois não se limita somente a essa doença, entretanto, desconhecemos qualquer citação dessa lesão em outra condição. Necrose hepática focal (Cullen 2007) e necrose aleatória de hepatócitos (Prescott et al. 2002, Stalker \& Hayes 2007), como visto nos casos aqui descritos, já foram relatadas há muitos anos por outros autores (Jubb \& Kennedy 1970, Niebele \& Cohrs 1970), assim como hipertrofia de células de Kupffer e presença de neutrófilos no interior dos sinusoides (Stalker \& Hayes 2007), outrora descrita pela expressão hepatite serosa (Niebele \& Cohrs 1970) e atualmente mais bem referida como hepatite reativa não específica (Cullen 2007) ou mudança reativa não específica (Geller \& Petrovic 2009a). Acredita-se que esses achados sejam decorrentes da reação hepática à bacteremia (Prescott et al. 2002). Aumento no número de mitoses e de hepatócitos binucleados também já foram descritas e talvez reflitam uma tentativa de regeneração hepática (Prescott 2007).

Os achados anatomopatológicos relacionados ao fígado são também semelhantes aos descritos em humanos há décadas (Geller \& Petrovic 2009b), principalmente no que se refere à célebre dissociação de hepatócitos (Beitzke 1916, Arean 1962). Para alguns autores (Brito 1968), essa alteração hepática não é uma lesão verdadeira, mas uma alteração pós-mortal, pois experimentalmente não é vista através de biópsia no período ante-morte (Ostertag 1950, Dotti \& Sabbioni 1959, Brito et al. 1967, Alves et al. 1987), apenas na necropsia, o que por muitos anos permitiu inferir de que se tratava de uma alteração agônica ou da aceleração do processo autolítico. Entretanto, estudos sistemáticos, que avaliaram a histologia do fígado diariamente (Alves et al. 1992), levaram a conclusão de que a lesão realmente ocorre em uma fase aguda da doença, mas posteriormente regride, e por isso talvez não seja observada na necropsia de todos os indivíduos afetados. Mais recentemente, uma diminuição da expressão de E-caderina na membrana plasmática dos hepatócitos de humanos com leptospirose, diagnosticada através da imuno-histoquímica em secções de fígado obtidos em necropsias realizadas até seis horas após a morte, tornou-se a mais recente explicação para a dissociação de hepatócitos (Brito et al. 2006).

Embora leptospirose ocorra ocasionalmente como uma doença hemolítica em filhotes de algumas espécies animais, como bovinos, ovinos, caprinos, suínos (Hunter 2004) e, talvez, rinocerontes-negros (Diceros bicornis) (Douglas \& Plue 1980), nos cães, leptospirose sempre foi vista como uma doença hepatorrenal e nunca como uma crise hemolítica (Center et al. 1990, Jones et al. 2000, Greene et al. 2006), entretanto, ocasionalmente, alguns autores ainda aventuram-se a citar tal patogênese para essa espécie (Serakides 2010). Com base na ausência de esplenomegalia e de lesões classicamente associadas à crise hemolítica intravascular (nefrose hemoglobinúrica, urina tingida de vermelho-tinto e embebição por hemoglobina) podemos afirmar que nenhum dos 53 cães desenvolveu crise hemolítica, entretanto, por algum motivo que não sabemos explicar, cerca de $25 \%$ dos cães tinham eritrócitos engolfados por células de Kupffer. Essa eritrofagia já havia sido descrita em casos de leptospirose humana (Brito et al. 1967) e talvez reflita uma hiperatividade das células de Kupffer hipertróficas em um fígado reativo, mas não de todo o sistema monocítico-macrofágico.

A icterícia vista na leptospirose é facilmente explicada pelo processo hemolítico (Fry \& MacGavin 2007, Prescott 2007), entretanto, como citamos no parágrafo anterior, cães, à semelhança de humanos, não desenvolvem hemólise e, portanto, essa não é a patogênese do acúmulo de bilirrubina nos tecidos dessas duas espécies. Assim, muitas teorias foram aventadas para explicar a icterícia da leptospirose em cães e humanos, principalmente com base na disfunção de hepatócitos, uma lesão a nível subcelular (Greene et al. 2006), que ocorreria por dificuldade em absorver (Sandborn et al. 1966), conjugar (Brito 1968) ou excretar (Brito et al. 1967) bilirrubina. Essas hipóteses baseavam-se em antigos estudos ultraestruturais que demonstravam alteração das microvilosidades do pólo sinusoidal (Sandborn et al. 1966) e do pólo canalicular (Brito et al. 1967). Mais recentemente, um estudo imuno-histoquímico (Brito et al. 2006) realizado em fígados de cobaios demonstrou que as leptospiras não estão presentes apenas nas células de Kupffer, mas também aderidas à membrana plasmática de hepatócitos, o que teoricamente poderia contribuir para disfunção relacionada ao metabolismo das bilirrubinas. A relação entre icterícia e necrose hepática, apontada como linearmente correspondente por alguns autores (Greene et al. 2006), não foi observada neste estudo, já que quase $80 \%$ dos cães tinham icterícia e apenas cerca de $30 \%$ demonstrou algum padrão de necrose na avaliação histológica do fígado.

No pulmão, lesões macroscópicas foram muito frequentes (cerca de $90 \%$ dos casos) e caracterizaram-se macroscopicamente por hemorragia e/ou edema. Em humanos, a verdadeira incidência do envolvimento pulmonar na leptospirose não é conhecida, mas lesões pulmonares são descritas em 20\%-70\% dos casos (O'Neil et al. 1991, Tattevin et al. 2005, Dolhnikoff et al. 2007). Embora não haja dados de prevalência sobre lesão pulmonar na leptospirose em cães, manifestação clínica foi recentemente descrita em $70 \%$ dos casos (Kohn et al. 2010) e é considerada comum em parte da Europa (Sykes et al. 2011), demonstrando que além de síndrome hepatorrenal, leptospirose é também uma doença pulmonar importante para essa espécie, embora não haja sequer uma citação sobre lesão pulmonar nos capítulos referente ao sistema respiratório dos dois mais célebres livros de patologia veterinária (Caswell \& Williams 2007, López 2007).

Algumas citações sobre anormalidades pulmonares, clínicas e radiológicas na leptospirose canina são encontradas na literatura internacional (Harkin \& Gartrell 1996, Birnbaum et al. 1998, Adin \& Cowgill 2000, Baumann \& Flückiger 2001, Goldstein et al. 2006) e em conjunto denominadas de síndrome hemorrágica pulmonar leptospiral (Sykes et al. 2011), mas os aspectos anatomopatológicos e a prevalência não são sequer abordados. Por muitos anos, hemorragia pulmonar foi a única lesão histológica reconhecida para a doença nessa espécie (Birnbaum et al. 1998), entretanto, recentemente (Kohn et al. 2010), deposição de fibrina intra-alveolar também foi descrita. Esses achados, 
em conjunto com edema, foram as lesões mais frequentemente encontradas por nós. Além disso, e ao contrário do que afirmam alguns autores (Greene et al. 2006), observamos com frequência um leve a moderado infiltrado inflamatório nos espaços alveolares, constituído principalmente por macrófagos e neutrófilos, um aspecto semelhante ao que foi descrito na doença humana (Ramachandran \& Perera 1977, Nicodemo et al. 1990).

Dos casos em que havia hemorragia pulmonar $(12 / 28$ $[42,9 \%])$, uma lesão bastante prevalente (5/12 [41,7\%]) foi a presença de agregados de neutrófilos, detritos celulares e trombos de fibrina obstruindo a luz dos microvasos pulmonares, que demonstravam graus variáveis de hialinização de suas paredes (necrose capilar fibrinoide), o que é conhecido em patologia humana como capilarite pulmonar (Green et al. 1996, Colby et al. 2001, Borges et al. 2005, Beasley 2010, Lara \& Schwarz 2010) e já foi descrito na leptospirose (Luks et al. 2003), mas até o momento não havia sido reconhecida para a doença em cães. É possível que esse seja um achado subrepresentado, devido a sua difícil visualização quando frente à hemorragia intensa (Abdulkader et al. 2002). Embora capilarite na leptospirose não tenha sido citada por nenhum trabalho científico ou livro de patologia veterinária, não é incomum observar essa lesão em imagens na literatura (Greene et al. 2006), entretanto, interpretada pelos autores com outras denominações, como pneumonia intersticial ou marginação de neutrófilos em pequenos vasos sanguíneos.

A ocorrência de sintomas pulmonares na leptospirose humana é reconhecida desde a década de 1950 (Silverstein 1953) e para alguns autores o envolvimento pulmonar pode ser a principal manifestação da doença em alguns casos (Poh \& Soh 1970, Im et al. 1989, Sehgal et al. 1995), principalmente na forma de síndrome da angústia respiratória aguda (SARA) (Berendsen et al. 1984, Allen et al. 1989, Alani et al. 1993, Emmanouilides et al. 1994, Simpson et al. 1998, Carvalho \& Bethlem 2002, Luks et al. 2003, Dolhnikoff et al. 2007), entretanto, a maior parte das revisões de literatura sobre SARA sequer trazem leptospirose com causa (Luks et al. 2003). Vários são os padrões histológicos que podem ocorrer em um quadro clínico de SARA, mas a lesão alveolar difusa (Ware \& Matthay 2000, Patel et al. 2004) e a hemorragia alveolar difusa (Im et al. 1989, Yersin et al. 2000, Patel et al. 2004) são os mais frequentemente descritos em humanos com leptospirose. Hemorragia alveolar difusa é uma expressão utilizada na literatura médica atual para se referir a uma síndrome clinicopatológica caracterizada por sangramentos que se originam na microvasculatura pulmonar (Dweik et al. 1997). Assim como outras síndromes, a hemorragia alveolar difusa é simplesmente uma manifestação de diversas doenças e o processo comum a todas elas é o sangramento intra-alveolar difuso (Albelda et al. 1985, Schwarz et al. 1994), quase sempre decorrente de capilarite (Lara \& Schwarz 2010).

Embora a patogênese da lesão alveolar difusa vista em humanos com leptospirose e que se apresentam com um quadro clínico de SARA não esteja estabelecida, talvez seja a mesma vista em outras infecções por bactérias Gram negativas, ou seja, indução indireta da ativação de neutrófilos e de células endoteliais, um processo caracterizado por aumento da avidez de ligação dos neutrófilos ao endotélio dos capilares pulmonares e mediado pela liberação de mediadores químicos (por exemplo, fator de necrose tumoral $\alpha$, leucotrieno $\mathrm{B}_{4}$ e interleucina-8) por monócitos e macrófagos pulmonares estimulados pelas endotoxinas (Kobzik 2000). Essa patogênese ganha força quando lembramos que leptospiras possuem lipopolissacarídeos reconhecidamente capazes de funcionar como endotoxinas (Vinh et al. 1986, Estavoyer et al. 1991, Souza \& Koury 1992, Dobrina et al. 1995, Lee et al. 2002) e embora ainda não seja comprovada, é suspeitada há décadas tanto para cães (Green et al. 1964, Keenan et al. 1978), quanto para humanos (Brito 1968) e cobaios (Faine 1957). Ultra-estruturalmente, danos às células endoteliais do pulmão de humanos também foram descritos (Nicodemo et al. 1997), e mais recentemente (Croda et al. 2010), uma base imunomediada foi proposta.

Neste trabalho, a imuno-histoquímica foi utilizada unicamente como método de inclusão dos casos a serem estudados. Os diferentes padrões morfológicos de imunomarcação foram semelhantes àqueles previamente descrito na literatura (Uip et al. 1992). Utilizando essa técnica, alguns autores (Wild et al. 2002, Ramachandran 2007) obtiveram aproximadamente $50 \%$ de positividade em rins de humanos e cães com leptospirose. Em contrapartida, imuno-histoquímica do músculo esquelético de humanos com leptospirose demonstrou muito maior (95\%) positividade (Uip et al. 1992). Imunomarcação foi observada em pouco menos de $70 \%$ do total de casos inicialmente selecionados, o que fez com que dos 79 casos diagnosticados como leptospirose, apenas 53 pudessem ser utilizados neste estudo. A perda da imunorreatividade por muitos antígenos está relacionada principalmente ao tempo de fixação e a temperatura dos procedimentos subsequentes (Ramos-Vara \& Beissenherz 2000). Infelizmente, em estudos retrospectivos torna-se difícil minimizar a influência desses fatores que tanto contribuem para a ocorrência de falso-negativos.

\section{CONCLUSÕES}

Os resultados apresentados demonstram a ocorrência de casos de leptospirose com apresentação anatomopatológica clássica, conforme descrito internacionalmente até a década de 1980, porém diferente em muitos aspectos do que vêm sendo atualmente observado nos Estados Unidos, Canadá e parte da Europa Ocidental.

A partir dos achados de necropsia, ressaltamos a importância em incluir leptospirose como uma causa de hemorragia e icterícia em cães da nossa região, ao contrário do que clínicos e patologistas possam depreender com base na literatura internacional corrente. Embora essas duas lesões sejam comuns a uma variedade de outras doenças, sua ocorrência simultânea na ausência de esplenomegalia é altamente indicativa de leptospirose, pois no cão, ao contrário do que ocorre em muitas outras espécies, a doença definitivamente não se comporta como um distúrbio hemolítico.

A partir dos achados anatomopatológicos observados no rim, recomendamos que a lesão renal vista em cães com leptospirose, e caracterizada por diferentes graus de dissociação degenerativo-inflamatória, seja considerada aguda 
ou subaguda e morfologicamente diagnosticada como nefrite tubulointersticial, conforme já o fazem alguns autores.

A partir dos achados anatomopatológicos observados no pulmão, recomendamos que a manifestação morfológica pulmonar vista em cães com leptospirose, e caracterizada por hemorragia, edema, inflamação e deposição de fibrina intra-alveolares, seja considerada uma lesão alveolar difusa e que na presença de agregados de neutrófilos nos microvasos e de necrose capilar seja morfologicamente diagnosticada como hemorragia alveolar difusa com capilarite, à semelhança de como vem sendo chamada em patologia humana.

A partir dos achados anatomopatológicos observados no fígado, consideramos que o conjunto das lesões visto em cães com leptospirose é etiologicamente inespecífico, pois apenas reflete bacteremia, não permitindo o diagnóstico definitivo da doença quando interpretado isoladamente, mas muito sugestivo dessa quando fazendo parte de um contexto em que há também lesões renais e pulmonares. Recomendamos que a lesão hepática vista em cães com leptospirose, e caracterizada por diferentes graus de dissociação de hepatócitos, colestase intra-canalicular, necrose hepatocelular individual, aleatória ou zonal, hipertrofia de células de Kupffer com ou sem eritrofagia, leucocitostase sinusoidal e aumento do número de hepatócitos binucleados e em mitose, seja morfologicamente diagnosticada como hepatite reativa não específica, à semelhança de como é chamado o processo inflamatório agudo e difuso do fígado em resposta a doenças sistêmicas, principalmente em patologia humana e menos frequentemente em patologia veterinária.

A partir dos achados anatomopatológicos observados no rim, no fígado e no pulmão podemos afirmar que leptospirose em cães na Região Central do RS ocorre quase que exclusivamente como uma doença aguda a subaguda. Finalmente, recomendamos que os critérios histopatológicos para o diagnóstico da leptospirose canina devem incluir a presença concomitante de nefrite tubulointersticial aguda ou subaguda, hepatite reativa não específica e lesão alveolar difusa, incluindo hemorragia alveolar difusa com capilarite, em um cão que durante a necropsia demonstrou icterícia, hemorragias e lesões extrarrenais de uremia na ausência de esplenomegalia.

Agradecimentos.- Ao Dr. Kurt Williams, patologista norte-americano do Diagnostic Investigation, College of Veterinary Medicine, Michigan State University, que auxiliou na interpretação e na validação das expressões utilizadas para definir as lesões pulmonares. Camila Tochetto e Mariana Martins Flores são bolsistas da Coordenação de Aperfeiçoamento de Pessoal de Nível Superior (CAPES) e do Conselho Nacional de Desenvolvimento Científico e Tecnológico (CNPq), respectivamente.

\section{REFERÊNCIAS}

Abdulkader R.C., Daher E.F., Camargo E.D., Spinosa C. \& Silva M.V. 2002. Leptospirosis severity may be associated with the intensity of humoral immune response. Revta Inst. Med. Trop. 44:79-83.

Adin C.A. \& Cowgill L.D. 2000. Treatment and outcome of dogs with leptospirosis: 36 cases (1990-1998). J. Am. Vet. Med. Assoc. 216:371375.

Adler B. \& De La Peña-Moctezuma A. 2010. Leptospira and leptospirosis. Vet. Microbiol. 140:287-296.
Alani F.S.S., Mahoney M.P., Ormerod L.P., Wright P.A. \& Garrues M. 1993. Leptospirosis presenting as atypical pneumonia, respiratory failure and pyogenic meningitis. J. Infect. 27:281-283.

Albelda S.M., Gefter W.B., Epstein D.M. \& Miller W.T. 1985. Diffuse pulmonary hemorrhage: a review and classification. Radiology 154:289-297.

Alexander A.D., Gleiser C.A., Malnati P. \& Yoder H. 1957. Observations on the prevalence of leptospirosis in canine populations of the United States. Am. J. Hyg. 65:43-56.

Allen P., Raftery S. \& Phelan D. 1989. Massive pulmonary haemorrhage due to leptospirosis. Intensive. Care Med. 15:322-324.

Alton G.D., Berke O., Reid-Smith R., Ojkic D. \& Prescott J.F. 2009. Increase in seroprevalence of canine leptospirosis and its risk factors, Ontario 1998-2006. Can. J. Vet. Res. 73:167-175.

Alves V.A.F., Vianna M.R., Yasuda P.H. \& De Brito T. 1987. Detection of leptospiral antigen in the human liver and kidney using an immunoperoxidase staining procedure. J. Pathol. 15:125-131.

Alves V.A.F., Gayotto L.C.C., De Brito T., Santos R.T.M., Wakamatsu A., Vianna M.R. \& Sakata E.E. 1992. Leptospiral antigens in the liver of experimentally infected guinea pigs and their relation to the morphogenesis of liver damage. Exp. Toxicol. Pathol. 44:425-434.

André-Fontaine G. 2006. Canine Leptospirosis-do we have a problem? Vet. Microbiol. 117:19-24.

Arean V.M. 1962. Studies on the pathogenesis of leptospirosis. I. A clinicopathologic evaluation of hepatic and renal function in experimental leptospiral infections. Lab. Invest. 11:273-288.

Avila M.O., Furtado L.R.I., Teixeira M.M., Rosado R.L.I., Martins L.F.S. \& Brod C.S. 1998. Aglutininas anti-leptospíricas em cães na área de influência do Centro de Controle de Zoonoses, Pelotas, RS, Brasil, no ano de 1995. Ciência Rural 28:107-110.

Barros C.S.L. \& Fighera R.A. 2011. Hepatite infecciosa canina. Revista Cães e Gatos. 26:10-16.

Baumann D. \& Flückiger M. 2001. Radiographic findings in the thorax of dogs with leptospiral infection. Vet. Radiol. Ultrasound 42:305-307.

Beasley M.B. 2010. The pathologist's approach to acute lung injury. Arch. Pathol. Lab. Med. 134:719-727.

Beitzke H. 1916. Ueber die pathologische Anatomie der ansteckenden Gelbsucht (Weilsche Krankheit). Klin. Wochenschr. 53:188-191.

Benoit C. 1970. Leptospirose aiguë chez un chien. Can. Vet. J. 11:81-83.

Berendsen H.H., Rommes J.H., Hylkema B.S., Meinesz A.F. \& Sluiter H.J. 1984. Adult respiratory failure with leptospirosis. Ann. Intern. Med. 101:402.

Birnbaum N., Barr S.C., Center S.A., Schermerhorn T., Randolph J.F. \& Simpson K.W. 1998. Naturally acquired leptospirosis in 36 dogs: Serological and clinicopathological features. J. Small Anim. Pract. 39:231-236.

Bolin C. 1996. Diagnosis of leptospirosis: a reemerging disease of companion animals. Semin. Vet. Med. Surg. Small. Anim. 11:166-171.

Borges E.R., Ab'Saber A.M. \& Barbas C.S.V. 2005. Síndromes hemorrágicas pulmonares. J. Bras. Pneumol. 31:36-43.

Braun J.L. 1961. Survey evidence of leptospira infection in Iowa dogs. J. Am. Vet. Med. Assoc. 138:90-98.

Brito T. 1968. On the pathogenesis of the hepatic and renal lesions in leptospirosis. Revta Inst. Med. Trop., São Paulo, 10:238-241.

Brito T., Marcondes Machado M., Montans S.O., Hoshino S. \& Frey-Müller E. 1967. Liver biopsy in human leptospirosis: A light and electron microscopy study. Virchows Arch. A, Pathol. Anat. Histopathol. 342:61-69.

Brito T., Menezes L.F. \& Lima D.M.C. 2006. Immunohistochemical and in situ hybridization studies of the liver and kidney in human leptospirosis. Virchows Arch. 448:576-583.

Brown C.A., Roberts W., Miller M.A., Davis A.D., Brow S.A., Bolin C.A., Jarecki-Black J., Greene E.C. \& Miller Liebl D. 1996. Leptospira interrogans serovar grippotyphosa infection in dogs. J. Am. Vet. Med. Assoc. 209:1265-1267.

Brown K. \& Prescott J.F. 2008. Leptospirosis in the family dog: A public health perspective. Can. Med. Assoc. 178:399-401. 
Bunch S.E. 2004. Distúrbios hepáticos agudos e sistêmicos que acometem o fígado, p.1398-1413. In: Ettinger S.J. \& Feldman E.C. (Eds), Tratado de Medicina Interna Veterinária: doenças do cão e do gato. Vol.2. 5aㅡ ed. Guanabara Koogan, Rio de Janeiro.

Carvalho C.R. \& Bethlem E.P. 2002. Pulmonary complications of leptospirosis. Rev. Clin. Chest. Med. 23:469-478.

Caswell J.L. \& Williams K.J. 2007. Respiratory system, p.524-653. In: Maxie M.G. (Ed.), Jubb, Kennedy, and Palmer's Pathology of Domestic Animals. Vol.2. $5^{\text {th }}$ ed. Saunders Elsevier, Philadelphia.

CDC 2012. Leptospirosis: Signs and symptoms in pets. Centers for Disease Control and Prevention <http://www.cdc.gov/leptospirosis/pets/ symptoms/index.html> Acesso em 29 jan. 2012.

Center S.A., Hornbucale W.E. \& Hoskins J.D. 1990. 0 fígado e o pâncreas, p.223-270. In: Hoskins J.D. (Ed.), Pediatria Veterinária: cães e gatos até seis meses de idade. Manole, São Paulo.

Chernesky S.J. 1970. A serologic survey for canine leptospirosis in British Columbia. Can. J. Comp. Med. 34:102-104.

Colby T.V., Fukuoka J., Ewaskow S.P., Helmers R. \& Leslie K.O. 2001. Pathologic approach to pulmonary hemorrhage. Ann. Diagn. Pathol. 5:309319.

Croda J., Neto A.N. \& Brasil R.A. 2010. Leptospirosis pulmonary haemorrhage syndrome is associated with linear deposition of immunoglobulin and complement on the alveolar surface. Clin. Microbiol. Infect. 16:593599.

Cullen J.M. 2007. Liver, biliary system and exocrine pancreas, p.393-461. In: Zachary F.J. \& McGavin D.M. (Eds), Pathologic Basis of Veterinary Disease. $4^{\text {th }}$ ed. Elsevier Mosby, St Louis.

Dobrina A., Nardon E. \& Vecile E. 1995. Leptospira icterohemorrhagiae and leptospire peptidolgycans induce endothelial cell adhesiveness for polymorphonuclear leukocytes. Infect. Immun. 63:2995-2999.

Dolhnikoff M., Mauad T., Bethlem E.P. \& Carvalho C.R.R. 2007. Pathology and pathophysiology of pulmonary manifestations in leptospirosis. Braz. J. Infect. Dis. 11:142-148.

Dotti F. \& Sabbioni G. 1959. Il quadro istomorfologico del fegato nelle lepitospirose benigna: studio bioptico com particolare riguardo alee forme anicteriche. Arch. Patol. Clin. Med. 36:81-101.

Douglas E.M. \& Plue R.E. 1980. Hemolytic anemia suggestive of leptospirosis in the black rhinoceros. J. Am. Vet. Med. Assoc. 177:921-923.

Dweik R.A., Arroliga A.C. \& Cash J.M. 1997. Alveolar hemorrhage in patients with rheumatic disease. Rheum. Dis. Clin. North Am. 23:395-410.

Emmanouilides C.E., Kohn O.F. \& Garibaldi R. 1994. Leptospirosis complicated by a Jarisch-Herxheimer reaction and adult respiratory distress syndrome: Case report. Clin. Infect. Dis. 18:1004-1006.

Estavoyer J.M., Racadot E. \& Couetdic G. 1991. Tumor necrosis factor in patients with leptospirosis. Rev. Infect. Dis.13:1245-1246.

Ettinger S.J. 1992. Tratado de Medicina Interna Veterinária: doenças do cão e do gato. $3^{\text {a }}$ ed. Manole, São Paulo. 1557p.

Ettinger S.J. \& Feldman E.C. 2004. Tratado de Medicina Interna Veterinária: doenças do cão e do gato. $5^{a}$ ed. Guanabara Koogan, Rio de Janeiro. 2156p.

Faine S. 1957. Virulence in leptospirae. I. Reactions of guinea pigs to experimental infection with Leptospira icterohaemorrhagiae. Brit. J. Exp. Pathol. 38:1-7.

Faine S., Adler B., Bolin C. \& Perolat P. 1999. Leptospira and Leptospirosis. $2^{\text {nd }}$ ed. Medsci, Melbourne. 272p.

Fighera R.A. \& Graça D.L. 2011. Sistema hematopoético, p.337-422. In: Santos R.L. \& Alessi A.C. (Eds), Patologia Veterinária. Roca, São Paulo.

Fighera R.A., Souza T.M., Silva M.C., Brum J.S., Graça D.L., Kommers G.D., Irigoyen L.F. \& Barros C.S.L. 2008. Causas de morte e razões para eutanásia de cães da Mesorregião do Centro Ocidental Rio-Grandense (19652004). Pesq. Vet. Bras. 28:223-230.

Fighera R.A., Souza T.M., Kommers G.D., Irigoyen L.F. \& Barros C.S.L. 2010. Patogênese e achados clínicos, hematológicos e anatomopatológicos da infecção por Rangelia vitalii em 35 cães (1985-2009). Pesq. Vet. Bras. 30:974-987.
Fry M.M. \& McGavin M.D. 2007. Bone marrow, blood cells and the linphatic system, p.698-771. In: McGavin M.D. \& Zachary F.J. (Eds), Pathologic Basis of Veterinary Disease. $4^{\text {th }}$ ed. Elsevier Mosby, St Louis.

Geller S.A. \& Petrovic L.M. 2009a. Biopsy Interpretation of the Liver. $2^{\text {nd }} e d$. Lippincott Williams and Wilkins, Philadelphia, p.62-70.

Geller S.A. \& Petrovic L.M. 2009b. Biopsy Interpretation of the Liver. $2^{\text {nd }} e d$. Lippincott Williams and Wilkins, Philadelphia, p.307-317.

Ghneim S.G., Viers J.H., Chomel B.B., Kass P.H., Descollonges D.A. \& Jhonson M.L. 2007. Use of a case-control study and geographic information systems to determine environmental and demographic risk factors for canine leptospirosis. Vet. Res. 38:37-50.

Goldstein R.E., Lin R.C., Langston C.E., Scrivani P.V., Erb H.N. \& Barr S.C. 2006. Influence of infecting serogroup on clinical features of leptospirosis in dogs. J. Vet. Intern. Med. 20:489-494.

Gough A. 2009. Diagnóstico Diferencial na Medicina Veterinária de Pequenos Animais. Roca, São Paulo. 447p.

Greene C.E. 2004. Doenças bacterianas, p.410-421. In: Ettinger S.J. \& Feldman E.C. (Eds), Tratado de Medicina Interna Veterinária: doenças do cão e do gato. Vol.1. 5a ed. Guanabara Koogan, Rio de Janeiro.

Green J.H., Arean V.M. \& Sarasin G. 1964. The pathogenesis of leptospirosis: toxin production by Leptospira icterohaemorrhagiae. Am. J. Vet. Res. 25:836-842.

Green R.J., Ruoss S.J., Kraft S.A., Duncan S.R., Berry G.J. \& Raffin T.A. 1996. Pulmonary capillaritis and alveolar hemorrhage. Update on diagnosis and management. Clin. Chest Med. 110:1305-1316.

Greene C.E., Sykes E.J., Brow A.C. \& Hartmann K. 2006. Leptospirosis, p.402-415. In: Greene C.E. (Ed.), Infectious Diseases of the Dog and Cat. $3^{\text {rd }}$ ed. Saunders Elsevier, St Louis. 1387p.

Harkin K.R. \& Gartrell C.L. 1996. Canine leptospirosis in New Jersey and Michigan: 17 cases (1990-1995). J. Am. Anim. Hosp. Assoc. 32:495-501.

Hoskins J.D. 1990. Pediatria Veterinária: cães e gatos até seis meses de idade. Manole, São Paulo. 605p.

Hrinivich K. \& Prescott J.F. 1997. Leptospirosis in two unrelated dogs. Can. Vet. J. 38:509-510.

Hubbert W.T. \& Shotts E.B. 1966. Leptospirosis in kennel dogs. J. Am. Vet. Med. Assoc. 148:1152-1159.

Hunter P. 2004. Leptospirosis, p.1445-1456. In: Coetzer J.A.W. \& Tustin R.C. (Eds), Infectious Diseases of Livestock. Vol.1. $3^{\text {rd }}$ ed. Oxford Univ. Press, Cape Town.

Im J., Yeon K.M., Han M.C., Kim C., Webb W.R., Lee J.S., Han Y.C. Chang W.H. \& Chi J.G. 1989. Leptospirosis of the lung: radiographic findings in 58 patients. Am. J. Roentgen. 152:955-959.

Inkelmann M.A., Rozza D.B., Fighera R.A., Kommers G.D., Graça D.L., Irigoyen L.F. \& Barros C.S.L. 2007. Hepatite infecciosa canina: 62 casos. Pesq. Vet. Bras. 27:325-332.

Inkelmann M.A., Anjos B.L., Kommers G.D., Fighera R.A. \& Barros C.S.L. 2008. Aspectos imunoistoquímicos da hepatite infecciosa canina. Ciência Rural 38:2636-2640.

Iwamoto E., Wada Y., Fujisaki Y., Umeki S., Jones M., Mizuno T., Itamoto K., Maeda K., Iwata H. \& Okuda M. 2009. Nationwide survey of Leptospira antibodies in dogs in Japan: Results from microscopic agglutination test and enzyme-linked immunosorbent assay. J. Vet. Med. Sci. 71:1191-1199.

Jimenez-Coello M., Vado-Solis I., Cárdenas-Marrufo M.F., Rodríguez-Buenfil J.C. \& Ortega-Pacheco A. 2008. Serological survey of canine leptospirosis in the tropics of Yucatan Mexico using two different tests. Acta Tropica 106:22-26.

Jones T.C., Hunt R.D. \& King N.W. 2000. Patologia Veterinária. 6aㅡ ed. Manole, São Paulo, p.423-513

Jubb K.V.F \& Kennedy P.C. 1970. Pathology of Domestic Animals. Vol.1. $2^{\text {nd }}$ ed. Academic Press, New York, p.297-406.

Kalin D.C., DiFruscia R., Lemay S. \& Higgins R. 1999. Three cases of canine leptospirosis in Quebec. Can. Vet. J. 40:187-191.

Keenan K.P., Alexander A.D. \& Montgomery C.A. 1978. Pathogenesis of experimental Leptospira interrogans, serovar bataviae, infection in the 
dog: Microbiological, clinical, haematological, and biochemical studies. Am. J. Vet. Res. 39:449-454.

Kobzik L. 2000. O pulmão, p.626-679. In: Contran R.S., Kumar V.E. \& Collins T. (Eds), Robbins, Patologia Estrutural e Funcional. $6^{\underline{a}}$ ed. Guanabara Koogan, Rio de Janeiro.

Kohn B., Steinicke K., Arndt G., Gruber A.D., Guerra B., Jansen A., Kaser-Hotz B., Klopfleisch R., Lotz F., Luge E. \& Nöckler K. 2010. Pulmonary abnormalities in dogs with leptospirosis. J. Vet. Intern. Med. 24:12771282.

Kravis E.M. \& Ivler D. 1961. A serologic survey of leptospira antibodies in an urban canine population. J. Am. Vet. Med. Assoc.138:24-26.

Langston C.E. \& Heuter K.J. 2003. Leptospirosis. A re-emerging zoonotic disease. Vet. Clin. North Am., Small Anim. Pract. 33:791-807.

Lappin M.R. 1992. Doenças bacterianas polissistêmicas, p.1000-1005. In: Nelson R.W. \& Couto C.G. (Eds), Medicina Interna de Pequenos Animais. Guanabara Koogan, Rio de Janeiro. 1084p.

Lara A.R. \& Schwarz M.I. 2010. Diffuse alveolar hemorrhage. Chest 137: 1164-1171.

Lee S.H., Kim S., Park S.C. \& Kim M.J. 2002. Cytotoxic activities of Leptospira interrogans hemolysin $\mathrm{SphH}$ as a poreforming protein on mammalian cells. Infect. Immun. 70:315-322.

Levett P.N. 2001. Leptospirosis. Clin. Microbiol. Rev. 14:296-326.

López A. 2007. Respiratory system, p.463-558. In: McGavin M.D. \& Zachary J.F. 2007. (Eds), Pathologic Basis of Veterinary Disease. $4^{\text {th }}$ ed. Mosby Elsevier, St Louis.

Lorenz M.D. 1996. Diagnóstico Clínico em Pequenos Animais. 2ª ed. Interlivros, Rio de Janeiro, p.1-11.

Luks A.M., Lakshminarayanan S. \& Hirschmann J.V. 2003. Leptospirosis presenting as diffuse alveolar hemorrhage: Case report and literature review. Chest 123:639-643.

Manninger R. \& Mócsy J. 1973. Hutyra, Marek, Menninger \& Mócsy, Patología y Terapéutica Especiales de los Animales Domésticos. Vol.1. 11르 ed. Labor, Barcelona, p.301-315.

Maxie N.G. 2007. Jubb, Kennedy, and Palmer's Pathology of Domestic Animals. Vol.2. $5^{\text {th }}$ ed. Sauders Elsevier, Philadelphia. 771p.

McGavin M.D. \& Zachary J.F. 2007. Pathologic Basis of Veterinary Disease. $4^{\text {th }}$ ed. Mosby Elsevier, St Louis. 1476p.

Meyer K.F., Stewart-Anderson B. \& Eddie B. 1939. Canine leptospirosis in United States. J. Am.Vet. Med. Assoc. 95:710-729.

Mikaelian I., Hoggins R., Lequient M.M., Lefebvre F. \& Martineau D. 1997. Leptospirosis in raccoons in Quebec: 2 case reports and seroprevalence in a recreational área. Can. Vet. J. 38:440-442.

Moore G.E., Guptill L.F., Glickman N.W., Caldanaro R.J., Aucoin D. \& Glickman L.T. 2006. Canine leptospirosis, United States, 2002-2004. Emerg. Infect. Dis. 12:501-503.

Nelson R.W. \& Couto C.G. 1992. Medicina Interna de Pequenos Animais. Guanabara Koogan, Rio de Janeiro. 1084p.

Newman J.P. 1950. Studies of canine leptospirosis. I. Evaluation of laboratory diagnostic procedures. II. Serologic determination of the incidence of latent infection in the Lansing, Michigan area. Am. J. Vet. Res. 11:405-411.

Newman S.J., Confer A.W. \& Panciera R.J. 2007. Urinary system, p.613-691. In: McGavin M.D. \& Zachary J.F. (Eds), Pathologic Basis of Veterinary Disease. $4^{\text {th }}$ ed. Mosby Elsevier, St Louis.

Nicodemo A.C., Del Negro G. \& Neto A.V. 1990. Thrombocytopenia and leptospirosis. Revta Inst. Med. Trop., São Paulo, 32:252-259.

Nicodemo A.C., Duarte M.I., Alves V.A., Takakura C.F., Santos R.T. \& Nicodemo E.L. 1997. Lung lesions in human leptospirosis: microscopic, imunohistochemical and ultrastuctural features related to trombocytopenia. Am. J. Trop. Med. Hyg. 56:181-187.

Nieberle K.E. \& Cohrs P. 1970. Anatomia Patológica Especial dos Animais Domésticos. Vol.1. 5⿳亠丷a ed. Fundação Calouste Gulbenkian, Lisboa, p.594696.

O’Neil K.M., Rickman L.S. \& Lazarus A.A. 1991. Pulmonary manifestations of leptospirosis. Rev. Infect. Dis. 13:705-714.
Ortega-Pacheco A., Colin-Flores R.F., Gutiérrez-Blanco E. \& Jiménez-Coello M. 2008. Frequency and type of renal lesions in dogs naturally infected with Leptospira species. Anim. Biodiv. Emerg. Dis. 1149:270-274.

Ostertag H. 1950. Leptospirosis icterohaemorrhacica in Bulgarien. Z. Hyg. Infektionskr. 131:482-500.

Patel S.R., Karmpaliotis D., Ayas N.T., Mark E.J., Wain J., Thompson B.T. \& Malhotra A. 2004. The role of open-lung biopsy in ARDS. Chest 125:197202.

Poh S.C. \& Soh C.S. 1970. Lung manifestations in leptospirosis. Thorax 25: 751-755.

Prescott J.F. 2007. Leptospirosis, p.481-490, within chapter written by Maxie M.G. \& Newman S.J., Urinary system, p.425-522. In: Maxie M.G. (Ed.), Jubb, Kennedy, and Palmer's Pathology of Domestic Animals. Vol.2. $5^{\text {th }}$ ed. Saunders Elsevier, Philadelphia.

Prescott J.F. 2008. Canine leptospirosis in Canada: A veterinarian's perspective. Can. Med. Assoc. 178:397-398.

Prescott J.F., Ferrier R.L., Nicholson V.M., Johnston M.K. \& Hoff B. 1991. Is canine leptospirosis underdiagnosed in southern Ontario? A case report and serological survey. Can. Vet. J. 32:481-486.

Prescott J.F., Key D. \& Osuch M. 1999. Leptospirosis in dogs. Can. Vet. J. 40:430-431.

Prescott J.F., McEwen B., Taylor J., Woods J.P., Abrams-Ogg A. \& Wilcock B. 2002. Resurgence of leptospirosis in dogs in Ontario: Recent findings. Can.Vet. J. 43:955-961.

Ramachandran R.J. 2007. Acute lung injury and leptospirosis. Brit. J. Anaesth. 99:44-145.

Ramachandran S. \& Perera M.V.F. 1977. Cardiac and pulmonary involvement in leptospirosis. Trans. R. Soc. Trop. Med. Hyg. 71:56-59.

Ramos-Vara J.A. \& Beissenherz M.E. 2000. Optimization of imunohistochemical methods using two different antigen retrieval methods on formalin-fixed, paraffin-embedded tissues: experience with 63 markers. J. Vet. Diagn. Invest. 12:307-311.

Rentko V.T., Clark N. \& Ross L.A. 1992. Canine leptospirosis: A retrospective study of 17 cases. J. Vet. Int. Med. 6:235-244.

Ribotta M., Fortin M. \& Higgins R. 2000. Canine leptospirosis: serology. Can. Vet. J. 41:494-495.

Sandborn E.B., Cóté M.G. \& Viallet A. 1966. Electron microscopy of a human liver in Weil's disease (Leptospirosis icterohaemorrhacica). J. Pathol. Bacteriol. 92:369-374.

Schwarz M.I., Cherniack R.M. \& King T.E.J. 1994. Diffuse alveolar hemorrhage and other rare infiltrative disorders, p.1889-1912. In: Murray J.F. \& Nadel J.A. (Eds), Textbook of Respiratory Medicine. W.B. Saunders, Philadelphia.

Searcy G.P. 1988. Hematopoietic system, p.269-310. In: Thomson R.G. (Ed.), Special Veterinary Pathology. Decker, Toronto.

Sehgal S.C., Murhekar M.V. \& Sugunan A.P. 1995. Outbreak of leptospirosis with pulmonary involvement in North Andaman. Indian. J. Med. Res. 102:9-12.

Serakides R. 2010. Sistema Urinário, p.291-336. In: Santos R.L. \& Alessi A.C. (Eds), Patologia Veterinária. Roca, São Paulo.

Silverstein C.M. 1953. Pulmonary manifestations of leptospirosis. Radiology 61:327-334.

Simpson F.G., Green K.A., Haug G.J. \& Brookes D.L. 1998. Leptospirosis associated with severe pulmonary haemorrhage in Far North Queensland. Med. J. Aust. 169:151-153.

Souza L. \& Koury M.C. 1992. Chemical and biological properties of endotoxin from Leptospira interrogans serovars canicola and icterohaemorrhagiae. Braz. J. Med. Biol. Res. 25:467-475.

Stalker J.M. \& Hayes M.A. 2007. Liver and biliar system, p.298-387. In: Maxie M.G. (Ed.), Jubb, Kennedy, and Palmer's Pathology of Domestic Animals. Vol.2. $5^{\text {th }}$ ed. Saunders Elsevier, Philadelphia.

Stokes J.E. \& Forrester S.D. 2004. New and unusual causes of acute renal failure in dogs and cats. Vet. Clin. North Am., Small. Anim. Pract. 34:909922. 
Swango L.J., Bankemper K.W. \& Kong L.I. 1992. Infecções bacterianas, ricketsiais, protozoais e outras, p.277-311. In: Ettinger S.J. (Ed.), Tratado de Medicina Interna Veterinária: doenças do cão e do gato. Vol.1. $3^{\mathrm{a}}$ ed. Manole, São Paulo.

Sykes J.E., Hartmann K., Lunn K.F., Moore G.E., Stoddard R.A. \& Goldstein R.E. 2011. 2010 ACVIM Small Animal Consensus Statement on Leptospirosis: Diagnosis, epidemiology, treatment, and prevention. J. Vet. Intern. Med. 25:1-13.

Tattevin P., Leveiller G., Flicoteaux R., Jauréguiberry S., Le Tulzo Y., Dupont M., Arvieux C. \& Michelet C. 2005. Respiratory manifestations of leptospirosis: A retrospective study. Lung 183:283-289.

Thiermann A.B. 1980. Canine leptospirosis in Detroit. Am. J. Vet. Res. 41:1659-1661.

Thomas R.E. \& Evans L.B. 1967. The distribution of leptospirosis in the German Shepherd dog population of the United States. J. Am. Vet. Med. Assoc. 150:33-36.

Thomson R.G. 1988. Special Veterinary Pathology. Decker, Toronto. 661p.

Uip D.E., Neto V.A. \& Duarte M.S. 1992. Diagnóstico precoce da leptospirose por demonstração de antígenos através de exame imuno-histoquímico em músculo da panturrilha. Revta Inst. Med. Trop., São Paulo, 34: 375-381.

Van De Maele I., Claus A., Haesebrouck F. \& Daminet S. 2008. Leptospirosis in dogs: A review with emphasis on clinical aspects. Vet. Rec. 163:409413.

Vinh T., Adler B. \& Faine S. 1986. Glycoprotein cytotoxin from Leptospira interrogans serovar Copenhageni. J. Gen. Microbiol. 132:111-112.

Ward M.P. 2002. Clustering of reported cases of leptospirosis among dogs in the United States and Canada. Prev. Vet. Med. 56:215-226.

Ward M.P., Guptill L.F., Prahl A. \& Wu C.C. 2004. Serovarspecific prevalence and risk factors for leptospirosis among dogs: 90 cases (1997-2002). J. Am. Vet. Med. Assoc. 224:1958-1963.

Ware L.B. \& Matthay M.A. 2000. The acute respiratory distress syndrome. N. Engl. J. Med. 342:1334-1349.

Warshawsky B., Lindsay R. \& Artsob H. 1998. Leptospirosis confirmed in three trappers in the Middlesex-London heath unit area. Publ. Health Epidemiol. Rep. Ontario 9:181-182.

Wild C.J., Greenlee J.J., Bolin C.A., Barnett J.K., Haake D.A. \& Cheville F. 2002. An improved immunohistochemical diagnostic technique for canine leptospirosis using antileptospiral antibodies on renal tissue. J. Vet. Diagn. Invest. 14:20-24.

Wohl J.S. 1996. Canine leptospirosis. Comp. Small. Anim. 18:1215-1224.

Yersin C., Bovet P., Mérien F., Clément J., Laille M., Van Ranst M. \& Perolat P. 2000. Pulmonary haemorrhage as a predominant cause of death in leptospirosis in Seychelles. Trans. R. Soc. Trop. Med. Hyg. 94:71-76. 